\title{
Productive Activities and Support Systems of Single Mothers
}

\section{Citation}

Hao, Lingxin and Mary C. Brinton. 1997. Productive activities and support systems of single mothers. American Journal of Sociology 102, no. 5: 1305-1344.

\section{Published Version}

http://dx.doi.org/10.1086/231085

\section{Permanent link}

http://nrs.harvard.edu/urn-3:HUL.InstRepos:3342978

\section{Terms of Use}

This article was downloaded from Harvard University's DASH repository, and is made available under the terms and conditions applicable to Other Posted Material, as set forth at http:// nrs.harvard.edu/urn-3:HUL.InstRepos:dash.current.terms-of-use\#LAA

\section{Share Your Story}

The Harvard community has made this article openly available.

Please share how this access benefits you. Submit a story.

\section{Accessibility}




\title{
Productive Activities and Support Systems of Single Mothers ${ }^{1}$
}

\author{
Lingxin Hao \\ Johns Hopkins University \\ Mary C. Brinton \\ University of Chicago
}

\begin{abstract}
Young single mothers' human capital development and labor market participation are important issues of public policy concern in the United States. This article uses a dynamic approach to model the determinants of single mothers' entry into and exit from productive activities. Using 14 waves of data from the National Longitudinal Survey of Youth, the article shows that kin coresidence facilitates young single mothers' entry into productive activities but does not play a significant role in sustaining participation. Women's individual trainability, the local labor market conditions, child support, and some family background factors all play a role. The results also demonstrate the insignificance of race and never-married versus evermarried status.
\end{abstract}

\section{INTRODUCTION}

Over the past two decades, there has been a divergence in married versus single mothers' labor force participation and school attendance. While employment has steadily increased among married mothers, especially those with young children, employment among single mothers has been stagnant since 1980 (U.S. Bureau of the Census 1995). The divergence is even greater when considering female recipients of Aid to Families with Dependent Children (AFDC), the cash assistance program for poor families prior to the 1996 welfare reform legislation. Female AFDC recipients' employment fell from 16\% in 1979 to 5\% in 1984 (Moffitt 1992) and remained low (6\%) in 1991 even after the reinforcement of the work and training requirement by the 1988 Family Support Act (U.S. House of Rep-

\footnotetext{
${ }^{1}$ The authors gratefully acknowledge the comments of David Hachen, V. Joseph Hotz, Michael Keen, Ross Matsueda, Kazuo Yamaguchi, and the AJS reviewers on earlier versions of the article. Direct all correspondence to Lingxin Hao, Department of Sociology, Johns Hopkins University, 3400 N. Charles St., Baltimore, Maryland 21218.

(C) 1997 by The University of Chicago. All rights reserved. 0002-9602/97/10205-0003\$01.50
} 
resentatives 1993). ${ }^{2}$ At the same time, the gap in educational attainment between women giving birth as teenagers versus as adults has increased (U.S. General Accounting Office 1994). The low employment rate and low educational attainment of single mothers both have a profound impact on their prospects for self-sufficiency and are therefore issues of great scholarly and public policy concern.

The absence of a husband means that a single mother must play the dual role of provider and nurturer, a task that is nearly impossible without some type of external support. Single mothers commonly rely on two types of support systems. One is public assistance, with AFDC as the most important program that was particularly targeted to single mothers and their children. The other support system is parents or kin who provide financial or in-kind assistance and, often, normative supervision. Research on single mothers' labor market participation has primarily focused on the first type of support rather than the second. But the absence of strong empirical evidence concerning the relationship between kin support and single mothers' labor force participation or other productive activities, such as school attendance, is an important lacuna in social science research. Meanwhile, the Personal Responsibility and Work Opportunity Reconciliation Act of 1996 focuses on ways that single mothers can be assisted to reach self-sufficiency. ${ }^{3}$ For example, the new welfare legislation requires states to deny AFDC benefits to single mothers under age 18 unless they live with their parents and are enrolled in school or in a training program. It is not known what the effect would be of a policy requiring single mothers to live with their parents or other adult kin. Would single mothers be more likely to enter the labor force or return to school, given the presence of other adults in the household? Would they be more likely to remain in these activities once they have entered them if other adults are present? Social science research to date has provided few guidelines on which to make these crucial assessments.

In this article, we seek to develop a theoretical framework to predict the role of kin support in single mothers' decisions to participate in productive

\footnotetext{
${ }^{2}$ The 1988 Family Support Act combines an emphasis on moving people into jobs with increased funding for the education and training believed necessary to make this possible. A program called Jobs Opportunity and Basic Skills (JOBS) allows working AFDC recipients to receive AFDC benefits for the first 12 months while working, even though the earnings may exceed the AFDC income eligibility threshold. In addition, JOBS increases child care assistance in order to facilitate AFDC recipients' employment.

${ }^{3}$ These attempts have been driven by the increase in the number of single mothers, rising welfare case loads, increased long-term dependency, and the growing share of single mothers on welfare who have never married (U.S. Bureau of the Census 1991; U.S. General Accounting Office 1994).
} 
activities outside the home. Our approach departs from previous research in four ways. First, we extend the focus of prior research to include school enrollment as well as employment. We do so because both of these activities have profound implications for single mothers' self-sufficiency and current policy concerns focus more on the distinction between productive and nonproductive activities than on the distinction among types of productive activities. Second, most previous studies have examined static and cross-sectional employment rather than the dynamics of labor market entry and exit. This article examines entry into and exit from productive activities as separate processes. This has great importance for the types of policy implications that arise. Do the same factors that promote single mothers' entry into the labor force or education also sustain participation, or do other variables assume greater importance in facilitating its continuation? Third, in examining the effects of kin support, we treat it as endogenous rather than as exogenous, in contrast to most previous research. And finally, prior research has generally not examined the reciprocal causal processes between participation in productive activities and kin support. We, however, use a dynamic model that considers the possible interdependence between these two.

The article is organized as follows. The second section briefly reviews the literature on support systems for single mothers and their effect on participating in productive activities. We develop a theoretical framework that integrates elements of microeconomic and sociological theory in order to make predictions about welfare and kin support. We also devote attention to other economic and social factors that may affect single mothers' productive activities, including individual characteristics (such as human capital and family background) and characteristics of the local economic and social environment (including welfare benefit levels, poverty rates, and unemployment rates). The third section describes the data used in the analysis and outlines the methods used to test the hypotheses. In the fourth section, we examine the consistency of the data with the predictions, assessing in particular whether kin support plays an important role in facilitating the entrance of young single mothers into productive activities and helping them to remain engaged. The final section summarizes our findings and outlines policy implications of the analysis.

\section{SUPPORT SYSTEMS FOR SINGLE MOTHERS}

Social scientists have extensively documented the negative health, social, and economic consequences produced by the dual role dilemma of single mothers. The responsibilities of being both a provider and a nurturer often interrupt a single mother's education, which in turn lowers her worth in both labor and marriage markets and increases her likelihood of being 
trapped in poverty and welfare dependence (Duncan, Featherman, and Duncan 1972; Krein and Beller 1986; McLanahan 1985; Hill, Augustyniak, and Ponza 1987; Furstenberg, Brooks-Gunn, and Morgan 1987; Bumpass and McLanahan 1989; Hao 1994, 1996). Recent studies on the economic consequences of out-of-wedlock child bearing have further confirmed that it has adverse economic consequences and that these effects differ substantially by race and across cohorts (Lundberg and Plotnick 1995; Geronimus and Korenman 1992; Bronars and Grogger 1994).

Single mothers often rely on government or kin support. About $35 \%$ of young single mothers received AFDC payments during 1985 (Hao 1995), and AFDC support was received by over three-quarters of all poor femaleheaded families in 1984 (Ellwood 1988). It has been estimated that between $48 \%$ and $69 \%$ of AFDC participants exit the AFDC program within two years, leaving a substantial minority who remain dependent for a longer period of time (Harris 1993).

Many single mothers receive substantial support from their parents or other kin in the form of coresidence, financial transfers, and child care. Stack (1974), Uehara (1990), and Edin (1991) have shown that poor women on public assistance must typically supplement AFDC with private support. ${ }^{4}$ Using a nationally representative survey of youth, Hogan, Hao, and Parish (1990) found that, in the mid-1980s, 56\% of black single mothers and $31 \%$ of white single mothers resided with adult kin; one-third of white single mothers and one-quarter of black single mothers received financial aid from kin that covered at least half of their living expenses; and two-thirds of single working mothers, black or white, had kinprovided child care assistance. Schoeni (1994) used another national survey to show that, in 1987, $28 \%$ of single-mother families received financial transfers from family and friends and 39\% received help in household work or child care from relatives and friends.

Welfare and kin support each provide single mothers with external support that can affect their decisions about engaging in productive activities. On balance, more is known about the effects of welfare than the effects of kin support.

\section{Welfare Support}

In microeconomics, welfare benefits and the attached tax rate on earnings are conceptualized as having two effects that reinforce each other on a person's decision to participate in the labor market. First, a higher level

\footnotetext{
${ }^{4}$ However, the generalizability of these studies is limited by the fact that they are usually based on specific communities and small samples.
} 
of welfare benefits may enable one to consume more without giving up nonmarket time. When the prices of consumer goods and nonmarket time are held constant, a higher benefit level will reduce the likelihood of employment. This is usually called the "income effect" and is familiar from the literature on married women's employment (where husband's higher income typically lowers a woman's probability of labor force participation). A second effect involves a change in the price of nonmarket time (or the opportunity costs of not working). If the price of nonmarket time decreases, a woman is less likely to work. This is usually called the "substitution effect" or "price-of-time effect." In the case of welfare participation, since the tax rate imposed on earnings lowers the price of nonmarket time, recipients have little incentive to work. Because the income effect and the substitution effect operate in the same direction, welfare has an unambiguous negative effect on work (Moffitt 1992).

The work disincentive effects of welfare have been extensively documented. The AFDC program provides cash payments to single mothers with children under age 18 if family income is below the eligibility threshold. An increase in AFDC benefits does not affect families with incomes far above the eligibility threshold because the gain from labor market participation remains much higher than the gain from the program. But increases in AFDC benefits affect families whose income is lower than or narrowly above the threshold. For example, a single mother working in the labor market full-time with a relatively low wage rate is not eligible for AFDC benefits and the accompanying Medicaid and housing subsidies. However, her market earnings may hardly exceed the combined welfare benefits as well as the costs related to work (child care, transportation, clothing, etc.). If a woman instead works part-time while participating in the program, the AFDC benefits are reduced dollar for dollar of the amount of earned income after four months of employment, and other assistance such as Medicaid is reduced or withdrawn. Therefore, for a single mother with a low earning capacity, working may produce less income than participating in the AFDC program. It makes little sense for her to use AFDC payments for child care costs in order to work, since the financial outcome of work will be a reduction in AFDC benefits (Jencks 1992).

Throughout the development of the AFDC program, researchers have conducted numerous evaluations using participants-only data, nationally representative samples, and large-scale social experiments. Many studies have shown that the AFDC program has a moderate negative effect on recipients' labor supply (see Moffitt [1992] for a review). But because school attendance does not disqualify the AFDC recipient and is not imposed with a tax rate, AFDC benefits should not have a price-of-time effect on schooling. Therefore, when we combine employment and school 
enrollment, AFDC benefits should still exemplify a case where unearned income produces a negative effect, which should be weaker than for the case of employment alone.

\section{Kin Support}

In microeconomics, financial, material, and in-kind transfers from kin are conceptualized as "unearned income." According to microeconomic theory, unearned income is expected to reduce market time but have no effect on the price of nonmarket time (the opportunity costs of not working). Under this conceptualization, kin support is predicted to have only an income effect that reduces market time.

Social capital theory challenges the microeconomic proposition with its emphasis on the normative expectations and obligations fostered in social relationships (Coleman 1988, 1990). We argue that kin support may change the price of nonmarket time through normative supervision and encouragement provided by kin for the single mother to achieve selfsufficiency and through the normative obligation of the single mother to fulfill these expectations.

Normative supervision and encouragement are hard to pick up in social surveys and are seldom measured. However, the situation where single mothers live in their parents' or other relatives' home may be the typical one where in-kind support and normative supervision and encouragement take place. ${ }^{5}$ We suggest that kin coresidence may change the price of a single mother's home time in three ways: (1) normative supervisioncoresidence may facilitate more effectively parents' and kin's expectations of the single mother and raise her obligation to fulfill these expectations by being engaged in productive activities; (2) child care assistance may be provided; and (3) exposure to the world of work - coresident kin may provide examples of the experience of a normal work routine and also may be helpful in providing information about jobs and access to social networks of employed friends and other kin. ${ }^{6}$ Coresidence could be initi-

\footnotetext{
${ }^{5}$ The positive effect of kin coresidence for single mothers can be substantiated by many ethnographic studies (Stack 1974; Uehara 1990; Lundgren-Gaveras 1991). However, kin coresidence in some instances may turn out to be a burden for single mothers, i.e., in the following situations: (1) parents/kin are ill behaved or abusive, (2) support needed by kin is greater than what kin can provide to the single mother (LundgrenGaveras 1991), and similarly (3) coresidence is for the purpose of pooling resources, with the single mother contributing more than parents and kin. At the same time, noncoresident kin, particularly those living in close proximity, may be able to provide normative supervision and encouragement for single mothers.

${ }^{6} \mathrm{We}$ are aware of potential conflict between parents and daughters, particularly when parents initiate assistance and impose supervision, but the prediction remains the same. In addition, while this study assumes that parents conform to social norms, we
} 
ated either by a single mother who wants to be self-supporting or by kin members who desire this outcome. Whoever initiates it, we would predict the outcome to be the same: kin coresidence should produce a dominant price-of-time effect and therefore increase the probability of productive activities in the market or in education. ${ }^{7}$

Normative supervision.-We argue that, when adolescent or young adult children have economic or personal difficulties, it is likely that many parents make transfers to their children not only out of a felt obligation to support them but also out of a desire to provide normative supervision. Supervision and encouragement from parents and kin are important in helping adolescents or members of the younger generation follow socially approved paths such as completing high school or higher education and obtaining appropriate employment (Goode 1961; Mueller and Pope 1977). A few sociological studies consider the motivations and outcomes of intergenerational transfers. Applying social exchange theory, Mutran and Reitzes (1984) emphasized the notion of intergenerational roles and the fact that roles and role outcomes are not fixed but are instead somewhat flexible and negotiable; when intergenerational transfers are made, a realignment of the hierarchy of roles often occurs. In the context we are considering, parents who provide room and board and other help may become influential in supervising their daughters' productive activities.

Provision of child care assistance. - The presence of an adult other than the husband in the household is positively correlated with women's work (Connelly 1989; Blau and Robins 1989; Parish et al. 1991). Child care by relatives, especially for young children, tends to be highly valued by parents (Mason and Kohlthau 1989). Klerman and Leibowitz (1990) have argued that the presence of family members in the household other than the husband who can substitute for the mother in child care promotes an earlier return to work for women who had worked before giving birth. ${ }^{8}$ In the case of single mothers, the provision of in-kind and child care assistance while residing together would presumably free up time for education and employment.

acknowledge that it is nevertheless important to keep in mind the possibility of negative influence from parents as well.

${ }^{7}$ Few studies in sociology have examined the impact of kin support on single mothers' labor market participation. Parish, Hao, and Hogan's study (1991) reported that kin support in the form of financial transfers, coresidence, and child care provision promotes the labor market participation of married but not single mothers. But because this study used only cross-sectional data, it could not delineate the effect of kin support on the processes of labor market entry and exit.

${ }^{8}$ They found that the presence of a grandmother significantly affected the mother's return to work within the first three months after birth. The importance of relative care, however, was attenuated after the first three months. 
Exposure to work and to social contacts. - Ethnographic studies have shown that many unemployed single mothers who live alone experience extreme social isolation from the world of paid work (Uehara 1990; Lundgren-Gaveras 1991). Living with parents and kin ends this isolation and may offer everyday exposure to the work routine of employed household members as well as to their contacts in the working world. Sociological and economic studies have demonstrated the importance of informal networks in the job search process (Marsden and Campbell 1990; Wegener 1991; Montgomery 1992, 1994). Kin coresidence may provide labor market contacts not only directly through the employed household members but also indirectly through these members' social ties.

Kin coresidence, however, is not something that is automatically available. Individual actors with different interests create and maintain such a living arrangement. Prior research on the determinants of kin coresidence has focused on whether it represents primarily a response to economic need or whether it tends to be a characteristic of the culture of particular race or ethnic groups. Some scholars report that the available economic resources relative to a family's basic needs explain away racial differences in living arrangements (Morgan 1982), whereas others find that both race/ethnicity and income are important determinants of kin networks (Tienda and Angel 1982). These inconsistencies in empirical research suggest the need for further examination of the determinants of kin coresidence and the need to incorporate kin coresidence as an endogenous variable affecting participation in productive activities. ${ }^{9}$

Empirical work examining the impact of kin support on employment suffers from four methodological problems. First is the possible reverse relationship between kin support and employment—does employment determine kin support (i.e., does a young woman's work or school enrollment lead her to request help from parents and kin?). Previous research has seldom considered the possible interdependence between kin support and participation in productive activities. Second is the issue of the endogeneity of kin support (i.e., kin support may be determined by a set of factors that also determine productive activities, an issue also seldom considered in previous research). Two additional problems are that empirical work has seldom examined the effect of kin support on school enrollment and has largely ignored the dynamic nature of women's productive activities.

Integrating microeconomic theory and social capital theory, we argued that kin support, particularly in the form of kin coresidence, could effec-

\footnotetext{
${ }^{9}$ Most sociological and ethnographic studies of kin support have focused on its prevalence according to race, ethnicity, socioeconomic status, family structure, and gender rather than on its motivations and effects.
} 
tively change the price of nonmarket time. In other words, because of the high value placed on working due to normative supervision and encouragement, together with the reduced child care costs resulting from kinprovided assistance and reduced costs in job searching due to parents' labor market attachment, the opportunity costs of not working should increase. Under this new conceptualization, kin coresidence is predicted to exert both an income effect and a price-of-time effect. Unlike the case of welfare, where the income and substitution effects operate in the same direction, in the case of kin support, the two effects operate in opposite directions. We suggest that, because of the higher value placed on working and the reduced costs of child care and job searching, it is likely that the price-of-time effect dominates, so that overall, kin support promotes participation in productive activities.

Our test of the effect of kin coresidence is made rigorous by modeling its endogeneity and considering its potential reverse relationship with productive activities. We also test for the role of noncoresident kin by examining whether kin support measured only in terms of financial transfers affects single mothers' entry into or exit from productive activities.

A number of other variables may also affect single mothers' participation in productive activities. Welfare support generally reduces the probability of productive activities (Moffitt 1992). But we expect that this effect may be relatively weak in our model since we include school enrollment, which AFDC does not penalize. Parental education and income are common measures of parental socioeconomic status and social class, which are related to the greater valuing of self-sufficiency for children (Kohn 1969). Thus a middle-class background may reinforce single mothers' intention to participate in productive activities.

Mother's employment when the respondent was a teenager reflects gender role socialization (Stockard and Johnson 1980). For a young mother, one effect of having had a working mother is that she was exposed to a woman who balanced commitments to work and to children. By virtue of this, we predict that this experience increases a single mother's propensity to engage in productive activities outside the home. Single mothers' schooling at first pregnancy and her "trainability" are measures of human capital that we use to predict participation in productive activities (Becker 1975). Marital history and number of children determine the opportunities and constraints of kin support. Never-married mothers have fewer economic resources than their ever-married counterparts and so are more likely to coreside with parents and kin. A large number of children would place a heavy burden on kin and may make kin coresidence less likely. More children also impose greater time constraints on single mothers' participation in productive activities, so we predict a negative effect of num- 
ber of children. Child support is a source of unearned income for single mothers and might enable them to purchase child care, thereby producing a dominant price-of-time effect on productive activities.

The local economic context is also important. We predict that higher unemployment rates and poverty rates lower the likelihood of single mothers' participation in productive activities. Unemployment rates reflect local employment opportunities and the probability of mismatches between available jobs and local residents' job qualifications. Poverty rates are a reflection of the degree of community isolation from mainstream social, occupational, and political institutions (Wilson 1987).

We realize that these explanatory variables do not exhaust all of the important factors that may affect productive activities and kin coresidence. For example, unobserved individual background differences and characteristics such as innate ability and personality traits may be associated with a woman's propensity to engage in productive activities. Having caring parents and relatives also increases the likelihood of coresidence. We therefore also include this unmeasured individual-specific heterogeneity in the model.

\section{DATA AND METHODS}

\section{Data}

We draw on 14 waves of the National Longitudinal Survey of Labor Market Experience, Youth Survey (NLSY) 1979-92. The NLSY is appropriate for our goals because it provides complete education and employment histories as well as detailed information on household members over a 14-year period; from this we can determine whether the respondent was living with adult kin. The longitudinal nature of the data also enables dynamic analyses. The NLSY sample of 12,686 young Americans ages 14-21 years old in January 1979 includes a national, probability-stratified random sample of 6,111 youths and a supplemental sample of 5,295 blacks, Hispanics, and economically disadvantaged whites (Center for Human Resource Research 1987a, 1987b). Thus we have a large sample of young single mothers over a fairly long period, during which the relationship between kin coresidence and productive activities can be rigorously modeled.

We are interested in the population of women who became single mothers either through an out-of-wedlock birth or through a divorce. Because unwed childbearing occurs in the teenage years and beyond and divorce occurs at various ages, we include all NLSY single mothers in our analysis. Both fertility and marital status are required to determine single motherhood status. The timing of a woman's first single motherhood spell is determined by the first unwed birth or the timing of first divorce given 
that she has had a marital birth. In our analysis, we consider those women who became first-time single mothers at some point during the 14 years of observation..$^{10}$ Second-time single motherhood spells are excluded from the analysis since they represent somewhat different experiences and difficulties from the first spells and only a small proportion of the single mothers in the analysis experienced a second spell during 1979-92. In the longitudinal framework, we include in the sample the entire period from the time a woman became a single mother for the first time until she married or until the end of the observational period. The length of a single motherhood spell therefore ranges from one to 14 years. We include in the analysis only those spells that are at least three years in length, for two reasons: ${ }^{11}$ (1) our dynamic model requires two previous states to include state dependence $(t-1)$ and duration effects $(t-2)$; and (2) our dynamic model deals with initial conditions by conditioning on the endogenous variables in the first two years of the processes (described below).

The resulting sample consists of 1,576 single mothers whose first spell of single motherhood was three to 14 years long during 1979-92, yielding 9,225 person years. We define productive activities as being either enrolled in school or being employed for at least $50 \%$ of the time between two interviews. ${ }^{12}$ We assign the value " 1 " if an individual spent at least $50 \%$

${ }^{10}$ It is likely that some women had become single mothers before 1979 by a birth out of wedlock or by the disruption of their first marriage. That is, for some single mothers, 1979 may not be the initial year of single motherhood. Also, entrance into the initial state of productive/nonproductive activities and coresidence/noncoresidence for a single mother, while not coterminous with the single motherhood spell, may have occurred before 1979. The potential resulting problems are related to "left censoring" (Tuma and Hannan 1984; Heckman and Singer 1986) and to "spells with unknown origin" (Hamerle 1991). Of the individuals in our sample, $15 \%$ were left censored, i.e., their single motherhood started before 1979. The majority of these left-censored individuals were never married and had long spells of single motherhood. While we have retrospective data on marriage, fertility, and employment prior to 1979, we do not have information on one of the dependent variables-kin coresidence-and many exogenous variables prior to 1979 , therefore we could not restore the entire spells for these left-censored spells in the analysis.

${ }^{11}$ About $24 \%$ of the NLSY single mothers experienced a single motherhood spell of two years or less. Excluding short single motherhood periods may mean that we include single mothers who have a lower probability of marrying, since single motherhood spells ending in marriage are shorter than censored single motherhood. To test for this sensitivity, we estimated a model that included spells of two years or longer (excluding the second-order state dependence). The results (not shown here) are largely the same as the results for single motherhood lasting at least three years. We further tested the sensitivity to eliminating the one-year spells by reducing our dynamic model to a pooled cross-sectional model; here the effect of coresidence was positive but weaker and marginally significant. In addition, we include in our model variables indicating married-out and censored-out as well as single motherhood duration.

${ }^{12}$ Sensitivity tests show that the signs of the estimates remain the same when different cut points are adopted. The positive effect of coresidence on entry into productive 
of her time between interviews in school or working and the value " 0 " otherwise. We choose $50 \%$ of the time as a cut point since it indicates a substantial amount of time and implies a serious commitment.

Kin coresidence is defined as living in the home of parents or other adult relatives, as reported at the time of each interview. Cases where parents or other relatives were living in the single mother's home are not considered as coresidence. We restrict the operational definition of kin support in this fashion so as to rule out the possibility that the single mother instead supports her parents or other kin. Additionally, because parents and other relatives headed the household, we can postulate that they were in a more powerful position than otherwise to provide effective normative supervision. Therefore, this measure is appropriate for our theoretical purposes. ${ }^{13}$ Although the survey provides a detailed week-byweek employment history and month-by-month school enrollment history, we use discrete-time measures of productive activities and kin coresidence with intervals between interviews, since kin coresidence and many timevarying explanatory variables such as community conditions were measured only at the time of each interview.

\section{A Model for the Interdependence of Two Endogenous Processes}

The analysis is designed to estimate the effects of kin coresidence on productive activities among single mothers in a longitudinal framework, taking into account the potential reverse causal relationship by specifying cross-lagged causal relationships between kin coresidence and productive activities. The longitudinal data on both coresidence and productive activities enable us to sort out the causal order between the two endogenous variables through constructing proper feedback effects for given individuals as they change status with respect to the two endogenous variables (Finkel 1995; Hsiao 1986).

We adopt a model advanced by Yamaguchi (1990) that uses a multinomial logit specification to model the interdependence of two discretestate endogenous processes. The dependent variable of the multinomial logit model is the cross-classification of the two endogenous variables. This model permits a cross-lagged causal analysis of the two endogenous

activities increases with higher cut points (from $10 \%$ to $90 \%$ with an increment of $10 \%$ in each test) and the effect is significant at the .05 level in all tests. Women who moved directly from school to work or vice versa with no intermediate nonproductive spell are treated as continuing productive activities.

${ }^{13}$ We tested whether an operational definition that includes cases where parents and kin lived in single mothers' households would make a difference. Results showed that the effect of kin coresidence on entry into productive activities remained positive but was somewhat weaker. 
processes and the simultaneous analysis of transitions between the two states of each process.

Using Yamaguchi's model, we developed a method that links multinomial logit parameters to the parameters that fit the two endogenous processes. This method allows us to model the interdependence of two endogenous processes using existing statistical packages. The converted estimates are simple linear combinations of the multinomial logit estimates; standard errors of the converted estimates can also be obtained through linear combinations of elements in the variance-covariance matrix of the multinomial logit estimates (see the appendix for a detailed technical exposition).

The dependent variable of the multinomial logit specification in our analysis is the cross-classification of productive activities and kin coresidence. This yields four outcomes: neither kin coresidence nor productive activities, only productive activities, only kin coresidence, and both. The transitions between the two discrete states are entry into and exit from productive activities and kin coresidence. We test the cross-lagged causal relationships between kin coresidence and productive activities in the past two periods and simultaneously analyze entry and exit, which is efficient since the potential differential effects of a particular covariate can be tested. We deal with initial conditions by conditioning on kin coresidence and productive activities at year 1 and year 2. Thus, our analysis starts from year 3, and our sample includes single motherhood spells that are at least three years long. ${ }^{14}$ Within each endogenous process, we consider both the state dependence of the immediate past period (first-order state dependence) and beyond the immediate past period (second-order state dependence). Yamaguchi (1990) shows that the second-order state dependence is equivalent (albeit with different scaling) to the duration effect beyond the immediate past period. ${ }^{15}$

Our discrete-time, discrete-state dynamic model includes individualspecific heterogeneity (Heckman 1981; Chamberlain 1985; Hsiao 1986; Maddala 1987). In addition to the substantive reason why we include individual-specific heterogeneity (as mentioned earlier), controlling for this heterogeneity is crucial to produce consistent estimates. First, because these propensities tend to be persistent over time, they cause the distur-

\footnotetext{
${ }^{14}$ Chamberlain (1978) suggests dealing with the initial conditions by conditioning on the state at year 1. See Corcoran and Hill (1985) for an empirical example. We extend Chamberlain's idea to condition on the states at year 1 and year 2 since we are also concerned with the duration effect that is captured by the state at $t-2$.

${ }^{15}$ This model is also called a "semi-Markov model," which allows the transition rate to be a function of the duration effect over and beyond the state dependence, captured by the state at $t-2$ (Bartholomew 1982; Yamaguchi 1990).
} 
bance terms to be serially correlated. Ignoring these individual-specific effects will lead to a failure to single out the true state dependence. Second, because these propensities are likely to be correlated with the lagged endogenous variables (both productive activities and kin coresidence), failure to control for them will lead to bias in the estimates, including those regarding our major hypothesis about the lagged causal effects of kin coresidence ${ }^{16} \mathrm{By}$ decomposing the error term into an individual-specific heterogeneity component and an independently and identically distributed stochastic component in the latent function underlying the $j$ th state of the multinomial logit model, we use a random-effect dynamic model, as shown below:

$$
\begin{aligned}
y_{i j t}^{*}= & \beta_{0 j}+\beta_{1 j} \mathrm{PD}_{i, t-1}+\beta_{2 j} \mathrm{KIN}_{i, t-1}+\beta_{3 j} \mathrm{PD}_{i, t-2}+\beta_{4 j} \mathrm{KIN}_{i, t-2} \\
& +\beta_{5 j}^{\prime} x_{i, t-1}+\beta_{6 j}^{\prime} z_{i}+\alpha_{i j}+\epsilon_{i j t},
\end{aligned}
$$

where $y_{i j}^{*}$ is the latent variable for individual $i$ in $j$ th state at time $t$, PD represents productive activities, KIN represents kin coresidence, $x_{i, t-1}$ is a vector of time-variant exogenous variables, $z_{i}$ is a vector of timeinvariant exogenous variables, $\beta$ 's are the corresponding parameters to be estimated, $\alpha_{i j}$ is the individual-specific heterogeneity in state $j$ and $\varepsilon_{i j t}$ is the independently, identically distributed disturbance term. This model is estimated using a maximum likelihood estimator. ${ }^{17}$

\section{Exogenous Variables}

We expect that welfare support lowers the probability that single mothers participate in productive activities. Welfare support is measured by the monthly state-level benefits from the AFDC program for a family consisting of an adult and a child. We have added to the NLSY data the maximum guarantee level of the AFDC program in the state in which the respondent resided at each wave of the 14-year period. The guarantee levels are thousands of constant 1989 dollars adjusted by the Consumer Price Index (CPI).

We expect that a woman's educational level and trainability, two measures of human capital, affect her schooling and employment. School enrollment is part of one of the endogenous variables, so, rather than using

\footnotetext{
${ }^{16}$ This is similar to the "omitted variable" or "misspecification" problem. The longitudinal data of NLSY that provide information on the intertemporal dynamics at the individual level can be utilized for a model including unobserved individual heterogeneity (Hsiao 1986).

${ }^{17}$ The program used to estimate this model, SON-of-CTM, was written by James Heckman, Steve Cameron, and George Yates. The authors gratefully acknowledge the permission to use the program.
} 
current schooling as an exogenous variable, we use years of schooling at first pregnancy. Trainability is measured by the Armed Forces Qualification Test (AFQT). We choose a subset of tests that are more important for women's than men's jobs such as word knowledge, paragraph comprehension, numerical operations, and coding speed (excluding arithmetic reasoning, auto and shop information, and mechanical comprehension). Since the scores are not normed by educational levels, we construct the percentile ranks of the selected AFQT scores among all female NLSY respondents with the same level of schooling. The percentile ranks should then represent trainability net of education effects.

We use a number of background variables including parents' education in years, yearly parental family income, family structure, and mother's employment status when the respondent was 14. Parents' education and family income are common measures of socioeconomic status and social class. Higher education, greater family income, and intact family structure represent the "middle class," which is more likely to adhere to mainstream norms and values; this thereby indirectly measures the degree of normative supervision. Mother's employment when the respondent was 14 is used as an indicator of gender role socialization that emphasizes mothers' participation in the public sphere. Parental socioeconomic status and mother's work status also indicate the degree of labor market attachment that key adult family members have demonstrated to their daughters. In sum, higher parental education, greater parental family income, intact family, and a working mother are predicted to lead to a greater likelihood of single mothers engaging in productive activities.

The model controls for demographic characteristics including race, age, marital history, number of children, and age of youngest child. We contrast whites and nonwhites (including blacks and Hispanics) because ethnographic studies have suggested more closely knit kin networks among minorities. We distinguish single mothers who were never married from those who were once married, hypothesizing that never-married mothers are more likely to live in the home of parents and kin. Women who are older, have fewer children, and have an older youngest child should have a higher probability of participating in productive activities outside the home. We also include the amount of yearly child support (in thousands of dollars) received and whether the single mother was living with a partner. Greater child support might promote productive activities since it enables the single mother to purchase child care and thereby produces a dominant price-of-time effect. Living with a partner reduces the possibility of living with parents or relatives and thereby lessens parents' supervision. Since the time spent in single motherhood may indicate the cumulative difficulties in handling the dual role of provider and nurturer, we include the number of years elapsed from the beginning of single motherhood, with 
the expectation of a negative impact on participation in productive activities. Also, since a substantial proportion of single motherhood periods are censored (i.e., remaining in single motherhood until the end of the observational period), we distinguish censored single motherhood from single motherhood that ended via marriage. Women who exited single motherhood through marriage were observed with the event occurring while women whose single motherhood is censored have lower probabilities of marriage; this is particularly the case for women with long single motherhood spell duration.

We include several variables that reflect the contextual social and economic situation that is likely to affect single mothers' productive activities: residence in urban areas and in the South, state-level unemployment rates, and county-level poverty rates. Urban areas (including suburban areas and cities of various sizes) and areas with low unemployment and poverty rates represent environments that offer greater opportunities for single mothers to participate in productive activities. We also control for region, given regional differences in the United States in factors such as religiosity and social norms that may reflect social control and ideas about selfsufficiency. Finally, we control for the idiosyncratic period effect of economic cycles and the political and social environment by adding a set of dummies representing the 14 years of observations.

We test for all interactions between each of the exogenous variables and each of the endogenous variables. If the original multinomial logit estimates for these interaction terms are statistically significant at the .10 level or better, we keep them in the equation. If the interaction term is kept for an exogenous variable, its effects are different for entry into and exit from the endogenous variable (resulting from different combinations of the main and interaction effects, see technical appendix). If the interaction term is eliminated for an exogenous variable, its effects on entry into and exit from the endogenous variable are the same in magnitude but opposite in sign.

\section{RESULTS}

Table 1 shows the proportion of the sample with single motherhood spells of three to six years length and seven to 14 years length, and the mean values of the endogenous and exogenous variables at the start of the single motherhood spell. About $44 \%$ of women in the sample had a single motherhood spell lasting less than six years, and the remainder had a spell lasting for a longer period. Women with longer spells were less likely to participate in productive activities than women with shorter spells. In contrast, women with longer spells were more likely to coreside with kin than women with shorter spells. 
TABLE 1

Descriptive Statistics of Variables at the Start of Single Motherhood, by Length of Single Motherhood Spells

\begin{tabular}{|c|c|c|c|}
\hline Variable & $3-6$ Years & $7-14$ Years & Total \\
\hline \multicolumn{4}{|l|}{ Endogenous: } \\
\hline \multirow[t]{2}{*}{ 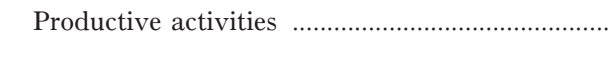 } & .51 & .25 & .45 \\
\hline & $(.50)$ & $(.49)$ & $(.50)$ \\
\hline \multirow[t]{2}{*}{ Kin coresidence } & .37 & .53 & .46 \\
\hline & $(.48)$ & $(.50)$ & (.50) \\
\hline \multicolumn{4}{|l|}{ Exogenous: } \\
\hline \multicolumn{4}{|l|}{ Individual characteristics: } \\
\hline \multirow[t]{2}{*}{ White ...... } & .43 & .25 & .33 \\
\hline & $(.50)$ & $(.44)$ & $(.47)$ \\
\hline \multirow[t]{2}{*}{ 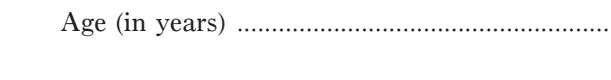 } & 23.2 & 20.4 & 21.6 \\
\hline & $(4.2)$ & $(2.6)$ & $(3.7)$ \\
\hline \multirow[t]{2}{*}{ Never married } & .61 & .84 & .74 \\
\hline & $(.49)$ & $(.37)$ & (.44) \\
\hline \multirow[t]{2}{*}{ Education at first pregnancy (in years) ............. } & 11.0 & 10.9 & 10.9 \\
\hline & (1.6) & $(1.7)$ & $(1.7)$ \\
\hline \multirow[t]{2}{*}{ Trainability (percentile) } & 42.3 & 32.6 & 36.9 \\
\hline & (26) & (25) & $(26)$ \\
\hline \multirow[t]{2}{*}{ 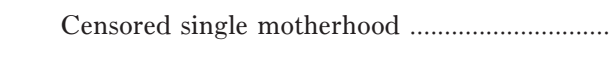 } & .35 & .78 & .59 \\
\hline & $(.48)$ & $(.41)$ & (.49) \\
\hline \multirow[t]{2}{*}{ No. of children } & 1.1 & 1.1 & 1.1 \\
\hline & $(.68)$ & $(.61)$ & (.64) \\
\hline \multirow[t]{2}{*}{ Age of youngest child (in years) } & 1.5 & .73 & 1.1 \\
\hline & $(2.2)$ & $(1.3)$ & $(1.8)$ \\
\hline \multirow[t]{2}{*}{ 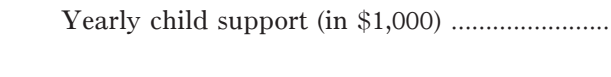 } & .32 & .25 & .28 \\
\hline & $(.97)$ & $(3.4)$ & (2.6) \\
\hline \multirow[t]{2}{*}{ Living with a partner } & .15 & .10 & .12 \\
\hline & $(.36)$ & $(.30)$ & $(.33)$ \\
\hline \multicolumn{4}{|l|}{ Family background: } \\
\hline \multirow[t]{2}{*}{ Yearly parental family income (in $\$ 1,000$ ) ..... } & 9.4 & 7.0 & 8.0 \\
\hline & $(10.2)$ & (6.9) & (8.6) \\
\hline \multirow{2}{*}{ Missing parental income } & .20 & .16 & .18 \\
\hline & $(.40)$ & $(.37)$ & $(.38)$ \\
\hline \multirow[t]{2}{*}{ No. of siblings } & 4.3 & 4.9 & 4.6 \\
\hline & $(2.7)$ & $(3.1)$ & $(3.0)$ \\
\hline \multirow[t]{2}{*}{ Parents' education (in years) } & 11.2 & 10.5 & 10.8 \\
\hline & $(2.8)$ & $(2.9)$ & $(2.9)$ \\
\hline \multirow[t]{2}{*}{ Intact family .... } & .56 & .46 & .51 \\
\hline & $(.50)$ & $(.50)$ & $(.50)$ \\
\hline \multirow[t]{2}{*}{ Mother working } & .48 & .46 & .47 \\
\hline & $(.50)$ & $(.50)$ & $(.50)$ \\
\hline
\end{tabular}


TABLE 1 (Continued)

\begin{tabular}{|c|c|c|c|}
\hline Variable & $3-6$ Years & $7-14$ Years & Total \\
\hline \multicolumn{4}{|l|}{ Contextual characteristics: } \\
\hline \multirow[t]{2}{*}{ County poverty rate } & .14 & .16 & .15 \\
\hline & $(.07)$ & (.09) & (.08) \\
\hline \multirow[t]{2}{*}{ State unemployment rate } & 7.5 & 8.1 & 7.8 \\
\hline & $(3.0)$ & $(3.3)$ & $(3.1)$ \\
\hline \multirow[t]{2}{*}{ Welfare support (in $\$ 1,000$ ) } & .32 & .34 & .33 \\
\hline & $(.14)$ & $(.16)$ & $(.15)$ \\
\hline \multirow[t]{2}{*}{ 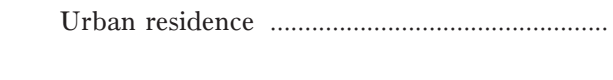 } & .80 & .81 & .81 \\
\hline & $(.40)$ & $(.39)$ & (.39) \\
\hline \multirow[t]{2}{*}{ Southern residence } & .42 & .41 & .41 \\
\hline & $(.49)$ & (.49) & (.49) \\
\hline$N$ & 697 & 879 & 1,576 \\
\hline 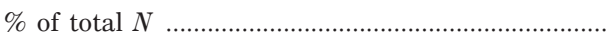 & 44.3 & 55.7 & 100 \\
\hline
\end{tabular}

SOURCE.-NLSY, 1979-92.

NotE.-SDs are in parentheses.

One-third of all single mothers were white. The proportion of whites among women who had longer single motherhood spells is much lower than for shorter spells (.25 and .43 respectively). The longer the spell, the lower is the woman's age at the start of it. ${ }^{18}$ This suggests that a woman is less likely to leave single motherhood if she enters this state at a younger rather than an older age. Women in longer single motherhood spells have lower trainability scores than women with shorter spells, although both groups are in the lower half of the percentile rankings. Compared to women with shorter single motherhood spells, women in longer single motherhood spells have younger children, less child support, and are less likely to live with a partner. Women experiencing longer single motherhood are also more likely to come from poorer, larger, broken families. In addition, women with longer single motherhood are likely to live in a poor community and in an area with higher unemployment rates and AFDC benefits.

Although the explanatory variables show distributional differences between shorter and longer single motherhood spells, our analysis shows that the responsiveness to the explanatory variables does not differ by

${ }^{18}$ The relatively older ages for both groups are due to the fact that the observation period starts in 1979, truncating the previous years for the $15 \%$ of women who had become single mothers prior to that year. 
length of spell (we tested for potential differential effects for shorter vs. longer lengths and found that these differences were close to zero and statistically insignificant). We therefore include in the final model only the variable indicating the years elapsed in single motherhood and exclude interaction terms.

Converted coefficients from the multinomial logit model are presented in table 2, which shows the effects on entry into and exit from productive activities, and table 4, which shows the effects on entry into and exit from kin coresidence. ${ }^{19}$ The coefficients in table 2 represent the effects on productive activities in two-way transitions, taking into account simultaneously the effects on kin coresidence and the effects on the association between productive activities and coresidence. The coefficients represent the effects of the explanatory variables on the log odds of the transition. To calculate the change in the odds of the transition due to one unit increase in the explanatory variable, we use the formula $\left(e^{\beta}-1\right)$. For example, consider the effect of kin coresidence on entry into productive activities (.138). This means that single mothers living with kin are $14.8 \%$ more likely to transit from nonproductive to productive activities than those who did not live with kin $\left(\left[\mathrm{e}^{\cdot 138}-1\right]=.148\right)$.

Examining the effects of endogenous variables in table 2, we find that kin coresidence in the immediate past period increases the probability of entering productive activities (.138 or a $14.8 \%$ increase compared to the noncoresidential situation), as predicted. This effect is statistically significant at the .05 level. Using data available in the NLSY, we also tested for the role of noncoresident kin by examining whether kin support measured in terms of financial transfers from these kin affect single mothers' entry into or exit from productive activities. The effect was close to zero and was not statistically significant. This offers additional support for our theoretical reasoning about why resident kin support should be important.

We explored the effect of coresident kin further by looking descriptively at the percentage of single mothers who were in coresidence households where at least one relative was in the labor force and by looking at the job search patterns of coresiding and noncoresiding single mothers. This information is available from the NLSY. Of single mothers coresiding with kin, $71 \%$ were in households where at least one kin member was gainfully employed. Furthermore, single mothers who lived with kin in 1981 were considerably more likely to be involved in a job search (34\%) than those who did not coreside (21\%); the gap is similar in $1982(47 \%$ vs. $37 \%$ ). More single mothers who lived with kin used friends or kin to

${ }^{19}$ Tables with the original multinomial logit estimates and converted coefficients are available on request from the authors. 
TABLE 2

Single Mothers' Entry into and Exit from Productive Activities

\begin{tabular}{|c|c|c|}
\hline Variable & Entry & Exit \\
\hline \multicolumn{3}{|l|}{ Endogenous: } \\
\hline Kin coresidence at $t-1$ & $\begin{array}{l}.138^{*} \\
(2.16)\end{array}$ & $\begin{array}{l}-.111 \\
(1.81)\end{array}$ \\
\hline 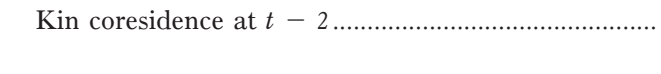 & $\begin{array}{l}.016 \\
(.57)\end{array}$ & $\begin{array}{r}-.016 \\
(.57)\end{array}$ \\
\hline \multicolumn{3}{|l|}{ Exogenous: } \\
\hline \multicolumn{3}{|l|}{ Individual characteristics: } \\
\hline White & $\begin{array}{r}-.007 \\
(.67)\end{array}$ & $\begin{array}{l}.007 \\
(.67)\end{array}$ \\
\hline 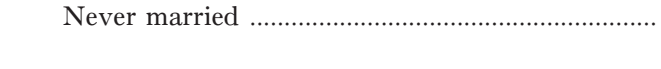 & $\begin{array}{r}-.037 \\
(.64)\end{array}$ & $\begin{array}{l}.037 \\
(.64)\end{array}$ \\
\hline 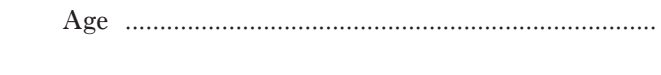 & $\begin{array}{l}.001 \\
(.05)\end{array}$ & $\begin{array}{l}-.075^{* *} \\
(4.74)\end{array}$ \\
\hline 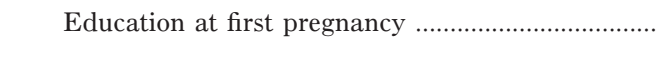 & $\begin{array}{l}.001 \\
(.12)\end{array}$ & $\begin{array}{r}-.001 \\
(.12)\end{array}$ \\
\hline 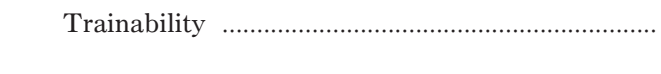 & $\begin{array}{l}.009 * * \\
(6.41)\end{array}$ & $\begin{array}{l}-.004 * * \\
(2.92)\end{array}$ \\
\hline No. of children, not coresident at $t-1 \ldots \ldots \ldots \ldots \ldots \ldots$ & $\begin{array}{l}-.072 \\
(1.15)\end{array}$ & $\begin{array}{l}.009 \\
(.14)\end{array}$ \\
\hline No. of children, kin coresident at $t-1 \ldots \ldots \ldots \ldots \ldots . . . .$. & $\begin{array}{l}-.164 * * \\
(2.69)\end{array}$ & $\begin{array}{r}.101 \\
(1.30)\end{array}$ \\
\hline Age of youngest child & $\begin{array}{l}.002 \\
(.15)\end{array}$ & $\begin{array}{r}-.002 \\
(.15)\end{array}$ \\
\hline Yearly child support & $\begin{array}{l}.054^{* *} \\
(3.13)\end{array}$ & $\begin{array}{l}-.054 * * \\
(3.13)\end{array}$ \\
\hline Living with a partner & $\begin{array}{l}-.019 \\
(1.11)\end{array}$ & $\begin{array}{r}.019 \\
(1.11)\end{array}$ \\
\hline Time spent in single motherhood & $\begin{array}{l}-.034^{*} \\
(2.00)\end{array}$ & $\begin{array}{c}.034^{*} \\
(2.00)\end{array}$ \\
\hline Censored single motherhood .... & $\begin{array}{c}-.001 \\
(.08)\end{array}$ & $\begin{array}{l}.001 \\
(.08)\end{array}$ \\
\hline Family background: & & \\
\hline Yearly parental income ................ & $\begin{array}{l}.016 * * \\
(4.06)\end{array}$ & $\begin{array}{l}-.016 * * \\
(4.06)\end{array}$ \\
\hline Missing parental income ............. & $\begin{array}{l}.074 \\
(.99)\end{array}$ & $\begin{array}{c}-.074 \\
(.99)\end{array}$ \\
\hline No. of siblings ......... & $\begin{array}{l}-.019 * \\
(2.05)\end{array}$ & $\begin{array}{c}.019 * \\
(2.05)\end{array}$ \\
\hline Parents' education ...................... & $\begin{array}{l}.008 \\
(.84)\end{array}$ & $\begin{array}{c}-.008 \\
(.84)\end{array}$ \\
\hline Intact family & $\begin{array}{l}.028 \\
(.56)\end{array}$ & $\begin{array}{c}-.028 \\
(.56)\end{array}$ \\
\hline Mother working & $\begin{array}{l}.112^{*} \\
(2.38)\end{array}$ & $\begin{array}{l}-.112 * \\
(2.38)\end{array}$ \\
\hline
\end{tabular}


TABLE 2 (Continued)

\begin{tabular}{|c|c|c|}
\hline Variable & Entry & Exit \\
\hline \multicolumn{3}{|l|}{ Contextual characteristics: } \\
\hline \multirow[t]{2}{*}{ County poverty rate $\times 10$. } & $-.141^{* *}$ & .051 \\
\hline & $(2.78)$ & $(.11)$ \\
\hline \multirow{2}{*}{ 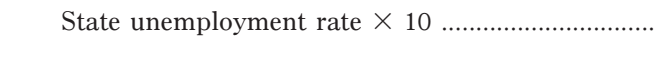 } & -.091 & .030 \\
\hline & $(1.20)$ & $(.34)$ \\
\hline \multirow[t]{2}{*}{ Welfare support } & -.279 & .219 \\
\hline & $(1.15)$ & $(1.29)$ \\
\hline \multirow[t]{2}{*}{ Urban residence } & .017 & .015 \\
\hline & $(.25)$ & $(.32)$ \\
\hline \multirow{2}{*}{ Southern residence } & $.226 * *$ & $-.171 * *$ \\
\hline & $(3.23)$ & $(3.37)$ \\
\hline \multirow[t]{2}{*}{ Constant } & $-1.911 * *$ & $1.701 * *$ \\
\hline & $(4.49)$ & $(5.61)$ \\
\hline \multirow[t]{2}{*}{ Unmeasured individual heterogenity ${ }^{\mathrm{a}} \ldots \ldots \ldots \ldots \ldots \ldots \ldots \ldots \ldots \ldots \ldots \ldots \ldots \ldots \ldots \ldots \ldots \ldots \ldots$} & $.703 * *$ & $-.703 * *$ \\
\hline & $(8.81)$ & $(8.81)$ \\
\hline
\end{tabular}

SOURCE.-NLSY, 1979-92.

Note.-Table shows the converted coefficients from the multinomial logit model. The absolute values of $t$-ratios are in parentheses.

${ }^{\text {a }}$ Estimated using a nonparametric extreme value distribution, where two support points were used and tested as appropriate.

$* P<.05$.

$* * P<.01$.

search for work than other single mothers $(23 \%$ vs. $17 \%$ in 1981 , with a similar gap in 1982 as well).

While kin coresidence seems to help single mothers start work or return to school, it does not play a significant role in helping them to remain productive. The effect of coresidence on exit from productive activities is in the predicted direction $(-.111$ or a $10.5 \%$ decrease) but is not statistically significant. ${ }^{20}$ This suggests that once a woman is enrolled in school or employed, it may be the job itself or the demands of the specific work organization or school that will have a more important impact than kin coresidence on whether she continues to be productive. We investigated the jobs of working females in the NLSY and found that, while $23 \%$ of women without children and $20 \%$ of married mothers have jobs in professional or managerial occupations, this is the case for only $13 \%$ of single mothers. In contrast, $21 \%$ of working women without children and $22 \%$

${ }^{20}$ The estimate of the effect of kin coresidence on single mothers' exit from productive activities is not very precise (due to a large standard error). This reduces our ability to draw inferences about this effect. Future research should pursue a definitive test of this effect using other data sets. The effect on both entry into and exit from productive activities of kin coresidence beyond the immediate past state is small and insignificant. 
of working married mothers are in service occupations, compared to $28 \%$ of working single mothers. When we further examined the occupations of women in different industries, we found that single mothers were more likely than other women to be in lower-status, lower-paying jobs within an industry. For example, among women employed in the "professional and related services" industry, $38 \%$ and $37 \%$ of married mothers and women without children, respectively, were in professional occupations; this contrasts with only $23 \%$ for single mothers. These findings suggest that the more unstable, lower-paying jobs that single mothers occupy may contribute to their exit, whether involuntary or voluntary, from productive activities. This is something on which kin support can have little effect.

Examining the effects of exogenous variables, we do not find important effects of race and marital history. Current public policy concerns focus especially on never-married single mothers. The majority of women in our sample never married (74\%), and many of the ever-married women were once teenage mothers. But the insignificance of the coefficient for never- versus ever-married mothers indicates that the two groups respond to kin and welfare support in a similar way once other variables are controlled. This calls into question whether single mothers should be selected out by marital history in policy discussions. The insignificance of race also obviously argues for the disutility of emphasizing race-or the oftaccompanying intimations of different behavioral responses to various factors by race-in the policy debate (see also Wilson 1987). Older women are not necessarily more likely to start productive activities, but they are less likely to quit them. Educational level at first pregnancy is not important after taking into account trainability and individual heterogeneity. Trainability does show a significant effect on participation in productive activities, with greater effects on entry $(.009$ or a $9.4 \%$ increase for every 10 percentile points) than on exit ( -.004 or a $4 \%$ decrease for every 10 percentile points). This suggests again that once enrolled in school or employed, the specific job or school will have a greater impact than human capital on whether women continue to be productive.

For single mothers in our sample, women living in adult kin's home with a larger number of children are less likely to enter productive activities (-.164, or a $15.1 \%$ decrease). Parents and kin may simply not have sufficient resources to lower the price of home time among single mothers with many children. The age of the youngest child has little effect on productive activities. This may reflect the fact that a large proportion of the women in our sample have preschool children, and there is, therefore, little variation in this variable. The amount of child support facilitates both entry into and the continuity of productive activities (.054 or a $5.5 \%$ increase per $\$ 1,000)$. We interpret this as indicating a price-of-time effect. 
In other words, some child care support should free up enough of women's time to make it more expensive not to be gainfully employed. Living with a partner, unlike living with a husband, has little effect on women's participation in productive activities. The longer the time elapsed in single motherhood, the less likely it is that a woman will enter into productive activities (-.034 or $3.3 \%$ less likely per year) and the more likely it is that she will exit from them at the same speed. The effect of censored single motherhood differs very little from the effect of single motherhood that ended via marriage. Family background characteristics also influence single mothers' productive activities. In particular, higher parental family income (.016 or a $1.6 \%$ increase per $\$ 1,000)$, fewer siblings $(-.019$ or a $1.9 \%$ decrease per sibling), and mother's labor force participation (.112 or an $11.9 \%$ increase) promote both entry into and continuity of productive activities.

A poor economic environment that is socially isolated, as indicated by high county poverty rates, inhibits single mothers' engagement in productive activities ( -.141 or a $13.2 \%$ decrease per 10 percentage points). However, poverty rates have no significant effect on exit. Unemployment rates also have little effect on both entry and exit. Although previous research has shown that AFDC benefit levels have negative effects on low-income women's employment (e.g., Moffitt 1992), our estimate for the effect on entry is negative (positive on exit) but is not significant. This is consistent with research based on more recent data (Hao and Leibowitz 1994; Hao, Klerman, and Leibowitz 1995) that shows that AFDC benefits do not significantly prevent single mothers with young children from working. Turning to regional differences, single mothers living in the South are more likely than those living in other regions to engage in productive activities (.226 or $25.4 \%$ more likely), which is consistent with previous research (Moffitt 1992). Since our model includes the effects of state-level unemployment rates, county-level poverty rates, and urban-rural differences, residence in the South may be proxying stronger social control mechanisms in that region, which lead single mothers to engage in productive activities, although this is only a supposition.

Table 2 also shows that the effect of the unmeasured individual heterogeneity is strong and significant, indicating that unobserved characteristics such as innate ability and personality traits are important in influencing both entry into and exit from productive activities. This is evidence of the importance of controlling for individual heterogeneity. Table 3 further illustrates this point. Here, we compare the results from a model with no control for heterogeneity and a model with such a control (we present only variables whose magnitudes and significance levels have changed). Two types of change can be observed. The first type involves an increase in magnitude and the significance level of the estimates. These include the 
TABLE 3

Significant Changes in Effects on Productive Activities

\begin{tabular}{|c|c|c|c|c|}
\hline \multirow[b]{2}{*}{ VARIABLE } & \multicolumn{2}{|c|}{$\begin{array}{c}\text { Without } \\
\text { HETEROGENEITY }\end{array}$} & \multicolumn{2}{|c|}{$\begin{array}{c}\text { With } \\
\text { HETEROGENEITY }\end{array}$} \\
\hline & Entry & Exit & Entry & Exit \\
\hline Time spent in single motherhood ........... & -.013 & .013 & $-.034 *$ & $.034 *$ \\
\hline 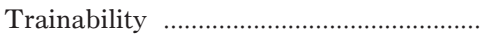 & & -.002 & & $-.004 * *$ \\
\hline Education at first pregnancy ....................... & $.094 * *$ & $-.094 * *$ & .001 & -.001 \\
\hline Censored single motherhood ...................... & $-.184 * *$ & $.184 * *$ & -.001 & .001 \\
\hline
\end{tabular}

SOURCE.-NLSY, 1979-92.

Note.-Only variables whose sign and significance level have changed are shown in the table.

$* P<.05$.

$* * P<.01$

effect of years elapsed in single motherhood on entry into productive activities (i.e., the estimate changes from -.013 and statistically insignificant to -.034 , statistically significant at the .05 level) and the effect of trainability on exit (from -.002, insignificant to -.004, significant at the .01 level). The second type of change is where a decrease in magnitudes and significance levels occurs. These changes include the effect of education at first pregnancy and the effect of censored single motherhood on entry into productive activities or exit from them. In sum, introducing an individualspecific component into the model does produce a change in the estimates for the effects of certain variables, but it does not change the effect of kin coresidence.

We posited that kin coresidence should facilitate the employment or school enrollment of single mothers. But we acknowledge that kin coresidence may instead be a response to productive activities - a way chosen by single mothers to cope with the time demands of schooling or a job. Our model tests this alternative simultaneously (see table 4). Productive activities either in the immediate prior period or before do not have a significant impact on the transition into or out of a coresidential situation. This supports the position that kin coresidence is not necessarily a response to the needs of single mothers who are already engaged in productive activities. Rather, living with kin, through its normative supervision and encouragement, potential in-kind transfers (room and board, child care assistance, and housework assistance), and possible role modeling and social access effects of labor market attachment appear to promote single mothers' productive activities.

Table 4 shows that kin coresidence is determined by a number of fac- 
TABLE 4

Single Mothers' Entry into and Exit from Kin Coresidence

\begin{tabular}{|c|c|c|}
\hline Variable & Entry & Exit \\
\hline \multicolumn{3}{|l|}{ Endogenous: } \\
\hline Productive activities at $t-1$ & $\begin{array}{l}.162 \\
(.77)\end{array}$ & $\begin{array}{r}-.151 \\
(.74)\end{array}$ \\
\hline 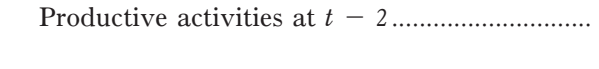 & $\begin{array}{l}-.034 \\
(1.41)\end{array}$ & $\begin{array}{r}.034 \\
(1.41)\end{array}$ \\
\hline \multicolumn{3}{|l|}{ Exogenous: } \\
\hline \multicolumn{3}{|l|}{ Individual characteristics: } \\
\hline White ……........................... & $\begin{array}{l}.005 \\
(.47)\end{array}$ & $\begin{array}{r}-.005 \\
(.47)\end{array}$ \\
\hline Never married & $\begin{array}{l}.153^{* * *} \\
(2.67)\end{array}$ & $\begin{array}{l}-.153^{* *} \\
(2.67)\end{array}$ \\
\hline \multicolumn{3}{|l|}{ Age: } \\
\hline Not productive at $t-1$ & $\begin{array}{l}.001 \\
(.03)\end{array}$ & $\begin{array}{c}-.001 \\
(.03)\end{array}$ \\
\hline Productive at $t-1$ & $\begin{array}{l}-.043 * * \\
(2.72)\end{array}$ & $\begin{array}{l}.043 * * \\
(2.72)\end{array}$ \\
\hline Education at first pregnancy ............................ & $\begin{array}{r}.012 \\
(1.90)\end{array}$ & $\begin{array}{l}-.012 \\
(1.90)\end{array}$ \\
\hline \multicolumn{3}{|l|}{ Trainability: } \\
\hline 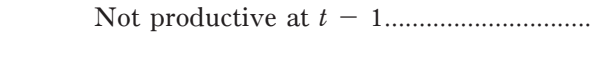 & $\begin{array}{l}-.003^{*} \\
(2.07)\end{array}$ & $\begin{array}{c}.003^{*} \\
(2.07)\end{array}$ \\
\hline Productive at $t-1 \ldots \ldots$ & $\begin{array}{l}-.003 \\
(1.94)\end{array}$ & $\begin{array}{r}.003 \\
(1.94)\end{array}$ \\
\hline \multicolumn{3}{|l|}{ No. of children: } \\
\hline Not productive at $t-1 \ldots \ldots \ldots \ldots \ldots \ldots \ldots \ldots \ldots \ldots$ & $\begin{array}{l}-.258 * * \\
(4.13)\end{array}$ & $\begin{array}{l}.156^{* *} \\
(2.58)\end{array}$ \\
\hline Productive at $t-1$ & $\begin{array}{l}-.070 \\
(1.13)\end{array}$ & $\begin{array}{r}-.032 \\
(.47)\end{array}$ \\
\hline Age of youngest child & $\begin{array}{r}-.002 \\
(.14)\end{array}$ & $\begin{array}{l}.002 \\
(.14)\end{array}$ \\
\hline Yearly child support & $\begin{array}{r}.032 \\
(1.24)\end{array}$ & $\begin{array}{l}-.032 \\
(1.24)\end{array}$ \\
\hline Living with a partner & $\begin{array}{l}-.030 \\
(1.67)\end{array}$ & $\begin{array}{r}.030 \\
(1.67)\end{array}$ \\
\hline Time spent in single motherhood ..................... & $\begin{array}{l}-.026 \\
(1.45)\end{array}$ & $\begin{array}{r}.026 \\
(1.45)\end{array}$ \\
\hline 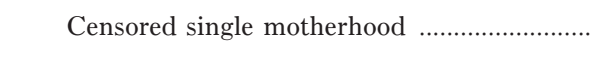 & $\begin{array}{r}.024 \\
(1.43)\end{array}$ & $\begin{array}{r}.024 \\
(1.43)\end{array}$ \\
\hline Family background: & & \\
\hline Yearly parental family income .... & $\begin{array}{l}.002 \\
(.64)\end{array}$ & $\begin{array}{c}-.002 \\
(.64)\end{array}$ \\
\hline Missing parental income & $\begin{array}{l}-.164 * \\
(2.50)\end{array}$ & $\begin{array}{c}.164^{*} \\
(2.50)\end{array}$ \\
\hline No. of siblings & $\begin{array}{c}-.004 \\
(.47)\end{array}$ & $\begin{array}{l}.004 \\
(.47)\end{array}$ \\
\hline
\end{tabular}


American Journal of Sociology

TABLE 4 (Continued)

\begin{tabular}{|c|c|c|}
\hline Variable & Entry & Exit \\
\hline 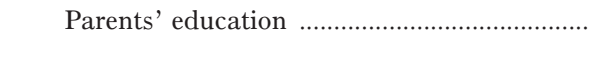 & $\begin{array}{r}-.003 \\
(.40)\end{array}$ & $\begin{array}{l}.003 \\
(.40)\end{array}$ \\
\hline Intact family & $\begin{array}{r}.054 \\
(1.26)\end{array}$ & $\begin{array}{l}-.054 \\
(1.26)\end{array}$ \\
\hline 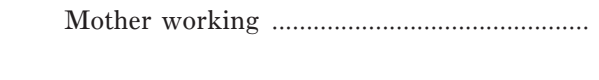 & $\begin{array}{r}.052 \\
(1.24)\end{array}$ & $\begin{array}{l}-.052 \\
(1.24)\end{array}$ \\
\hline $\begin{array}{l}\text { Contextual characteristics: } \\
\quad \text { County poverty rate } \times 10\end{array}$ & & \\
\hline Not productive at $t-1$ & $\begin{array}{l}.100 \\
(.20)\end{array}$ & $\begin{array}{r}-.100 \\
(.20)\end{array}$ \\
\hline Productive at $t-1$ & $\begin{array}{l}.478 \\
(.95)\end{array}$ & $\begin{array}{c}-.478 \\
(.95)\end{array}$ \\
\hline 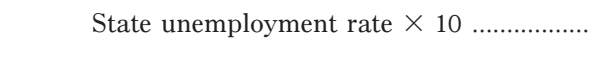 & $\begin{array}{l}-.019 * \\
(2.43)\end{array}$ & $\begin{array}{l}.019 * \\
(2.43)\end{array}$ \\
\hline 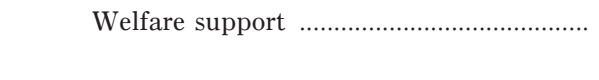 & $\begin{array}{l}.067 \\
(.30)\end{array}$ & $\begin{array}{r}-.067 \\
(.30)\end{array}$ \\
\hline 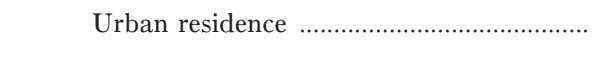 & $\begin{array}{l}.062 \\
(.96)\end{array}$ & $\begin{array}{r}-.062 \\
(.96)\end{array}$ \\
\hline 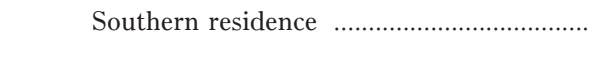 & $\begin{array}{r}.112 \\
(1.64)\end{array}$ & $\begin{array}{l}-.112 \\
(1.64)\end{array}$ \\
\hline 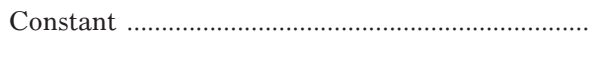 & $\begin{array}{r}-.119 \\
(.29)\end{array}$ & $\begin{array}{l}.119 \\
(.29)\end{array}$ \\
\hline Unmeasured individual heterogenity ${ }^{\mathrm{a}} \ldots \ldots \ldots \ldots \ldots \ldots . . . . . . . .$. & $\begin{aligned} .135 \\
(1.37)\end{aligned}$ & $\begin{array}{l}-.135 \\
(1.37)\end{array}$ \\
\hline
\end{tabular}

SOURCE.-NLSY, 1979-92.

NoTE.- Table shows the converted coefficients from the multinomial logit model. The absolute values of $t$-ratios are in parentheses.

${ }^{a}$ Estimated using a nonparametric extreme value distribution, where two support points were used and tested as appropriate.

$* P<.05$.

$* * P<.01$.

tors. First, never-married women, who have fewer economic resources than their ever-married counterparts, are more likely to coreside with parents and kin (.153 or $16.5 \%$ more likely). Second, older women who were engaged in productive activities in the past year are less likely to live with kin (-.043 or $4.2 \%$ less likely), indicating that coresidence is an agesensitive phenomenon, particularly when the woman can support herself. Third, women with higher trainability when nonproductive are less likely to move into their parents' home $(-.003$ or a $3 \%$ decrease per 10 percentile points), perhaps because they anticipate a greater ability to deal with their dual role problems. Fourth, women with more children who are also nonproductive are less likely to coreside with parents $(-.258$ or $22.7 \%$ less 
TABLE 5

Significant Changes in Effects on Kin Coresidence Due to Inclusion of Heterogeneity

\begin{tabular}{|c|c|c|c|c|}
\hline \multirow[b]{2}{*}{ VARIABLE } & \multicolumn{2}{|c|}{$\begin{array}{c}\text { Without } \\
\text { Heterogeneity }\end{array}$} & \multicolumn{2}{|c|}{$\begin{array}{c}\text { With } \\
\text { Heterogeneity }\end{array}$} \\
\hline & Entry & Exit & Entry & Exit \\
\hline Never married & .064 & -.064 & $.153 * *$ & $-.153 * *$ \\
\hline White $. . . \ldots \ldots \ldots \ldots \ldots . . . . . . .$. & $-.228 * *$ & $.228 * *$ & .005 & -.005 \\
\hline Age, nonproductive at $t-1 \ldots \ldots \ldots \ldots \ldots$ & $-.026^{*}$ & $.026 * *$ & .001 & -.001 \\
\hline Censored single motherhood ....................... & $.193 * *$ & $-.193 * *$ & .024 & -.024 \\
\hline Southern residence & $.119 *$ & $-.119 *$ & .112 & -.112 \\
\hline
\end{tabular}

SOURCE.-NLSY, 1979-92.

Note.-Only variables whose sign and significance level have changed are shown in the table.

$* P<.05$.

$* * P<.01$.

likely per child). This may be because parents and kin simply do not have unlimited resources to support a large family, particularly when this family has no income. Fifth, missing parental income, which indicates the absence of parents or parents' unwillingness to report income, lowers the likelihood of coresidence (-.164 or a $15.1 \%$ decrease). Sixth, higher unemployment rates, depicting a difficult economic environment, inhibit parents and kin from providing coresident help (-.019 or a $1.9 \%$ decrease per 10 percentage points). Finally, we note that the amount of child support does not have a statistically significant effect on coresidence. This suggests that coresidence cannot be regarded as a simple substitute for the provision of child care funds.

The message from table 4 is that, when all the exogenous factors are taken into account, demands from single mothers' participation in productive activities do not lead to kin coresidence. Including kin coresidence as an endogenous variable in the model offers a clear test that the possibility of a causal link from productive activities to kin coresidence can be eliminated.

Unmeasured heterogeneity has no significant effect on kin coresidence, but including it in the model does change some of the estimates (see table 5 ). The never-married effect on entry into kin coresidence increases from .064 (statistically insignificant) to .153 (significant at the .01 level). Conversely, decreases in magnitude and significance levels occur for four variables: race (the effect of being white), age while nonproductive, censored single motherhood, and residence in the South. 
American Journal of Sociology

\section{CONCLUSION}

Our analysis reveals a number of significant findings regarding the conditions of single motherhood and the implications for single mothers' participation in gainful employment or in schooling. The younger a woman is when she becomes a single mother, the longer she is likely to remain in single motherhood. Women with the longest single motherhood spells are also the most likely to come from large, poor families that were not intact when the woman was a teenager. These results underline the significance of the social and economic context from which a woman enters and remains in single motherhood. Moreover, our causal model reveals that the longer a woman spends in single motherhood, the less likely she is to enter productive activities and the more likely she is to exit from them once she starts. Kin coresidence substantially increases the likelihood that single mothers will move from nonproductive to productive activities. Its effect is comparable to the effect of other important factors. For example, the effect of kin coresidence is equivalent to the effect from a $\$ 2,556$ increase in child support per year. Similarly, kin coresidence's effect is equivalent to the effect of an increase of 15.3 percentile points in mothers' individual trainability, or that of an $11.4 \%$ decrease in county-level poverty rate.

A number of policy implications stem from the results of our models, and these concern what does and does not exert a significant effect on single mothers' participation in productive activities. Our confidence in these results and the policy implications is strengthened by the ability of our dynamic model to take into account the potential reverse causal effect of kin coresidence and the endogeneity of kin coresidence.

The first policy implication is that, although kin support in the form of coresidence does indeed promote single mothers' entry into productive activities, there is no strong evidence from our data supporting the idea that kin coresidence can prevent single mothers from exiting such activities. ${ }^{21}$ In other words, kin coresidence alone cannot sustain single mothers' productive activities. We interpret the lack of a significant effect on sustained productive activities as a possible reflection of the greater importance of two sets of factors. The first is the demand side of the labor market. The characteristics of the jobs that single mothers are able to find and of the firms where they work most likely have an important effect on how long they can keep their jobs. Single mothers are less likely than either women without children or married mothers to hold jobs in the

\footnotetext{
${ }^{21}$ This finding echoes a recent study of public support (JOBS) showing that welfare recipients who volunteered for the job training program had only a $50 \%$ chance of staying employed through the first year after training (Shogren 1994).
} 
more stable, high-skill sector of the labor market. Second, the responsibilities of single parenthood coupled with the lack of a reliable child care system may prevent single mothers from keeping their jobs. For example, if a child becomes ill while the mother is still in a probationary period on her job, missing work to care for the sick child or to take the child to the doctor may jeopardize her job status. Even for mothers who are beyond the probationary period, intensive care for children may force them to quit their jobs. While coresident kin may provide assistance as well as encouragement for a single mother to enter into productive activities, it is after this occurs that the child care burden falls on coresident kin; they may not be able to provide full-blown, day-to-day assistance, especially during difficult times such as when a child falls ill. Unavailability of child care and its high cost plus the responsibility of bringing up a child as a single parent may be the two most important labor supply-side reasons why single mothers leave the labor force.

Although the Personal Responsibility and Work Opportunity Reconciliation Act of 1996 offers a combination of job training, time limits on welfare, work requirements, child care subsidies, and child support enforcement to single mothers in order to encourage them to be independent, exactly how these measures are to be implemented is not clear. Under the Family Support Act of 1988, child care arrangements for working AFDC recipients have often been inadequate and unstable. Notably, our results show that the amount of child support exerts a significant positive effect on single mothers' probability of entering into and remaining in productive activities. Child support is for the care and well-being of the child. While we did not directly assess the effect of public child care subsidies, our finding about child support not only speaks for the importance of regulating child support but also implies that more adequate and stable public child care assistance can have a significant effect on the probability of drawing single mothers into productive activities and maintaining their presence there.

A second set of findings is in regard to the determinants of kin coresidence itself. Our results show that the probability of coresidence is not affected by the amount of child support. In other words, we find no basis on which to argue that coresidence should be regarded as a natural substitute for monetary child support. Rather, coresidence is a multidimensional situation that may provide single mothers with adult working role models and encouragement to work or resume education. As such, it may be well to explore ways of encouraging coresidence but the conclusion that it should be mandated is not supported by our findings.

Third, the positive effect of trainability on single mothers' entrance into and continuation of productive activities merits attention. Obviously, 
greater attention needs to be devoted to what types of programs do and do not enhance individuals' long-term trainability, particularly the ability to learn more advanced skills while on the job.

Fourth, even though the effect of welfare support on single mothers' productive activities is negative, the effect is not statistically significant. This is probably due to the fact that welfare does not penalize schooling, which we included in our analysis as an important productive activity. By using a more complete model that considers both welfare and kin support in a dynamic framework, we generate a more precise estimate for the welfare effect. This is particularly useful if we are concerned with the self-sufficiency and productivity of single mothers. Our findings suggest that less time should be spent on acrimonious debates about the level of welfare payments and more emphasis should be put instead on determining the most useful combinations of assistance, including child care assistance.

Fifth, neither race nor never-married versus ever-married status has a significant effect on either entry into or exit from productive activities in our model. This finding merits attention because policy debates are so often underlaid by assumptions about differential behavioral responses based on race and never-married status.

Finally, our findings point to the importance of environmental factors in promoting or discouraging young single mothers' participation in productive activities outside the home. Living in an area of high poverty has a dampening effect. Wilson (1987) points out that joblessness and social isolation in inner-city areas are linked to long-term welfare dependency and other social problems. Because of their low income, single mothers often live in grim economic and social environments. Our analysis shows that the likelihood of entering productive activities is greater when local economic and social conditions are better. Furthermore, kin coresidence is more likely when unemployment rates are lower. These findings argue for the importance of policies designed to generate greater local employment opportunities that benefit not only single mothers and their children but their communities as well. This is obviously a formidable challenge, but one reinforced by the findings of this article.

\section{APPENDIX}

\section{Technical Note}

The purpose of this appendix is to show the relationships between multinomial logit parameters and parameters that fit the two endogenous variables under the model Yamaguchi (1990) advanced. This method should make it easier to model reciprocal causality using existing statisti- 
TABLE A1

Cross-Classification of Two

VARIABLES

\begin{tabular}{rrrr}
\hline \hline & & \multicolumn{2}{c}{$B$} \\
\cline { 3 - 4 } & & & \\
\cline { 3 - 4 }$A$ & & -1 & 1 \\
\hline-1 & $\ldots \ldots \ldots \ldots \ldots \ldots \ldots . . . \ldots$ & $P_{00}$ & $P_{01}$ \\
1 & $\ldots \ldots \ldots \ldots \ldots \ldots \ldots$ & $P_{10}$ & $P_{11}$ \\
\hline
\end{tabular}

cal packages. The method converts multinomial logit parameters into parameters of interest and their standard errors.

To begin, suppose we have two dichotomous random variables $A$ and $B$, which take the value of either -1 or 1 . Cross-classifying the two variables, we have four categories (see table A1), where $P_{00}=\operatorname{prob}(A=-1$ and $B=-1), P_{01}=\operatorname{prob}(A=-1$ and $B=1), P_{10}=\operatorname{prob}(A=1$ and $B=-1)$, and $P_{11}=\operatorname{prob}(A=1$ and $B=1)$.

For simplicity, we have two covariates, $X_{1}$ and $X_{2}$, and $\delta$ stands for their corresponding parameters. A multinomial logit specification is, then,

$$
\begin{aligned}
& \log \left(\frac{P_{01}}{P_{00}}\right)=\delta_{20}+\delta_{21} X_{1}+\delta_{22} X_{2}, \\
& \log \left(\frac{P_{10}}{P_{00}}\right)=\delta_{30}+\delta_{31} X_{1}+\delta_{32} X_{2}, \\
& \log \left(\frac{P_{11}}{P_{00}}\right)=\delta_{40}+\delta_{41} X_{1}+\delta_{42} X_{2} .
\end{aligned}
$$

The outcome $(A=-1$ and $B=-1)$ is the reference category, and its parameters, $\delta_{1}$, are constrained to zero.

Let $\mu, \phi^{A}, \phi^{B}$, and $\phi^{A B}$ represent a set of parameters that is defined as the following:

$$
\begin{aligned}
& \log P_{00}=\mu-\phi^{A}-\phi^{B}+\phi^{A B}, \\
& \log P_{01}=\mu-\phi^{A}+\phi^{B}-\phi^{A B}, \\
& \log P_{10}=\mu+\phi^{A}-\phi^{B}-\phi^{A B}, \\
& \log P_{11}=\mu+\phi^{A}+\phi^{B}+\phi^{A B} .
\end{aligned}
$$


Through algebraic manipulation of equations in (A2), we get

$$
\begin{gathered}
4 \phi^{A}=-\log \left(\frac{P_{01}}{P_{00}}\right)+\log \left(\frac{P_{10}}{P_{00}}\right)+\log \left(\frac{P_{11}}{P_{00}}\right), \\
4 \phi^{B}=\log \left(\frac{P_{01}}{P_{00}}\right)-\log \left(\frac{P_{10}}{P_{00}}\right)+\log \left(\frac{P_{11}}{P_{00}}\right), \\
4 \phi^{A B}=-\log \left(\frac{P_{01}}{P_{00}}\right)-\log \left(\frac{P_{10}}{P_{00}}\right)+\log \left(\frac{P_{11}}{P_{00}}\right) .
\end{gathered}
$$

The set of parameters to explain $A, B$, and their association, $A B$, is a function of the covariates, $X_{1}$ and $X_{2}$ :

$$
\begin{aligned}
4 \phi^{A} & =4 \lambda_{0}^{A}+4 \lambda_{1}^{A} X_{1}+4 \lambda_{2}^{A} X_{2}, \\
4 \phi^{B} & =4 \lambda_{0}^{B}+4 \lambda_{1}^{B} X_{1}+4 \lambda{ }_{2}^{B} X_{2}, \\
4 \phi^{A B} & =4 \lambda_{0}^{A B}+4 \lambda_{1}^{A B} X_{1}+4 \lambda_{2}^{A B} X_{2} .
\end{aligned}
$$

Substituting equations (A1) and (A4) into equation (A3), we can solve for the parameters corresponding to each covariate. For example, for the parameters corresponding to $X_{1}$, we have equation (A5), where the parameters that fit $A, B$, and their association $A B$ can be expressed as linear combinations of the multinomial logit parameters:

$$
\begin{aligned}
4 \lambda_{1}^{A} & =-\delta_{21}+\delta_{31}+\delta_{41}, \\
4 \lambda_{1}^{B} & =\delta_{21}-\delta_{31}+\delta_{41}, \\
4 \lambda_{1}^{A B} & =-\delta_{21}-\delta_{31}+\delta_{41} .
\end{aligned}
$$

Since the variance of a linear combination of random variables is the sum of the variance of each variable and twice the covariance among them (adjusting for the scaling and the signs), the corresponding variance for a particular parameter can be expressed as linear combinations of elements in the variance-covariance matrix of the multinomial logit estimation. For the variances of parameters corresponding to $X_{1}$, we get

$$
\begin{aligned}
\operatorname{var}\left(4 \lambda_{1}^{A}\right)= & \operatorname{var}\left(\delta_{21}\right)+\operatorname{var}\left(\delta_{31}\right)+\operatorname{var}\left(\delta_{41}\right)-2 \operatorname{cov}\left(\delta_{21}, \delta_{31}\right) \\
& -2 \operatorname{cov}\left(\delta_{21}, \delta_{41}\right)+2 \operatorname{cov}\left(\delta_{31}, \delta_{41}\right), \\
\operatorname{var}\left(4 \lambda_{1}^{B}\right)= & \operatorname{var}\left(\delta_{21}\right)+\operatorname{var}\left(\delta_{31}\right)+\operatorname{var}\left(\delta_{41}\right)-2 \operatorname{cov}\left(\delta_{21}, \delta_{31}\right) \\
& +2 \operatorname{cov}\left(\delta_{21}, \delta_{41}\right)-2 \operatorname{cov}\left(\delta_{31}, \delta_{41}\right), \\
\operatorname{var}\left(4 \lambda_{1}^{A B}\right)= & \operatorname{var}\left(\delta_{21}\right)+\operatorname{var}\left(\delta_{31}\right)+\operatorname{var}\left(\delta_{41}\right)+2 \operatorname{cov}\left(\delta_{21}, \delta_{31}\right) \\
& -2 \operatorname{cov}\left(\delta_{21}, \delta_{41}\right)-2 \operatorname{cov}\left(\delta_{31}, \delta_{41}\right) .
\end{aligned}
$$


So far, we have established the relationships between the multinomial logit parameters and the parameters that fit the two endogenous variables. This model considers only one point in time. Note that this model cannot handle the reciprocal causal relationship between the two endogenous variables. Below, we introduce the time dimension and specify the model in the longitudinal framework. By including the lagged endogenous variables on the right-hand side of the equation, we will be able to model the reciprocal cross-lagged causation.

Consider a single endogenous variable in a longitudinal framework first. Repeated measures of the endogenous variable $A$ for each individual over time describe an endogenous process $A_{t}$, which takes a state ( -1 or 1 ) at time $t$, where $t=1, \ldots, T$. To deal with the initial condition, Chamberlain (1978) suggests conditioning on the state at $t=1$. Within the process, two-way transitions are possible: from $A_{t-1}=-1$ to $A_{t}=1$ and from $A_{t-1}=1$ to $A_{t}=-1$. To consider state dependence, we specify a first-order state dependence, $A_{t-1}$. (We also include the second-order state dependence, $A_{t-2}$, which captures the duration effect beyond the immediate state in the article.)

When we consider two endogenous processes simultaneously, we have two endogenous processes, $A_{t}$ and $B_{t}$. We add to the model the effects of $B_{t-1}$ on $B_{t}$. For $B_{t}$, we similarly have two-way transitions: from $B_{t-1}=$ -1 to $B_{t}=1$ and from $B_{t-1}=1$ to $B_{t}=-1$. We will first assume that the effects are equal in magnitude (but opposite in sign) for both ways of transitions and then relax this assumption later.

When we specify the dynamic model as a function of the lagged state of each of the two endogenous processes, we at the same time specify the cross-lagged reciprocal causal relationships between $A_{t}$ and $B_{t}$ (i.e., the model includes the effect of $B_{t-1}$ on $A_{t}$, and the effect of $A_{t-1}$ on $\left.B_{t}\right)$. The model extends equation (A4) to the following:

$$
\begin{aligned}
4 \phi^{A_{t}} & =4 \lambda_{0}^{A}+4 \lambda_{1}^{A} A_{t-1}+4 \lambda_{2}^{A} B_{t-1}+4 \lambda_{3}^{A} X_{1}+4 \lambda_{4}^{A} X_{2}, \\
4 \phi^{B_{t}} & =4 \lambda_{0}^{B}+4 \lambda_{1}^{B} A_{t-1}+4 \lambda_{2}^{B} B_{t-1}+4 \lambda_{3}^{B} X_{1}+4 \lambda_{4}^{B} X_{2}, \\
4 \phi^{A B_{t}} & =4 \lambda_{0}^{A B}+4 \lambda_{1}^{A B} A_{t-1}+4 \lambda_{2}^{A B} B_{t-1}+4 \lambda_{3}^{A B} X_{1}+4 \lambda_{4}^{A B} X_{2},
\end{aligned}
$$

where $\lambda_{1}^{A}$ is the first-order state dependence for $A_{t}, \lambda_{2}^{A}$ is the lagged causal effect of $B_{t-1}$ on $A_{t}, \lambda_{3}^{A}$ and $\lambda_{4}^{A}$ are the parameters related to the two covariates. Similarly, $\lambda_{1}^{B}$ is the lagged causal effect of $A_{t-1}$ on $B_{t}, \lambda_{2}^{B}$ is the firstorder state-dependence for $B_{t}, \lambda_{3}^{B}$ and $\lambda_{4}^{B}$ are the parameters related to the two covariates. The parameters for the association between $A_{t}$ and $B_{t}$ are expressed by $\lambda^{A B}$.

To specify the multinomial logit model for cross-lagged reciprocal causal relationship between two endogenous variables, we cross-classify 
$A_{t}$ and $B_{t}$, obtain a four-category dependent variable. The multinomial logit specification for the two interdependent processes is shown below:

$$
\begin{aligned}
& \log \left(\frac{P_{01}}{P_{00}}\right)=\delta_{20}+\delta_{21} A_{t-1}+\delta_{22} B_{t-1}+\delta_{23} X_{1}+\delta_{24} X_{2}, \\
& \log \left(\frac{P_{10}}{P_{00}}\right)=\delta_{30}+\delta_{31} A_{t-1}+\delta_{32} B_{t-1}+\delta_{33} X_{1}+\delta_{34} X_{2}, \\
& \log \left(\frac{P_{11}}{P_{00}}\right)=\delta_{40}+\delta_{41} A_{t-1}+\delta_{42} B_{t-1}+\delta_{43} X_{1}+\delta_{44} X_{2} .
\end{aligned}
$$

According to equation (A5), we can express the parameters in equation (A7) as linear combinations of the multinomial logit parameters in equation (A8). By the same token, the standard errors of the parameters in equation (A7) can be obtained using equation (A6). For example, the lagged causal effect of $B_{t-1}$ on $A_{t}$ is $\lambda_{2}^{A}$, which can be expressed as:

$$
4 \lambda_{2}^{A}=-\delta_{22}+\delta_{32}+\delta_{42},
$$

and its variance is

$$
\begin{aligned}
\operatorname{var}\left(4 \lambda_{2}^{A}\right)= & \operatorname{var}\left(\boldsymbol{\delta}_{22}\right)+\operatorname{var}\left(\boldsymbol{\delta}_{32}\right)+\operatorname{var}\left(\boldsymbol{\delta}_{42}\right)-2 \operatorname{cov}\left(\boldsymbol{\delta}_{22}, \boldsymbol{\delta}_{32}\right) \\
& -2 \operatorname{cov}\left(\boldsymbol{\delta}_{22}, \boldsymbol{\delta}_{42}\right)+2 \operatorname{cov}\left(\boldsymbol{\delta}_{32}, \boldsymbol{\delta}_{42}\right) .
\end{aligned}
$$

A more rigorous modeling is to relax the assumption that the effects on the two ways of transitions are equal in magnitude. Interactions between the two lagged endogenous variables will capture the differential effects for the two ways of transitions (see Yamaguchi 1990). For simplicity, we suppress the covariates. The reciprocal causal model for $A_{t}$ and $B_{t}$ is

$$
\begin{aligned}
\phi^{A_{t}} & =\lambda_{0}^{A}+\lambda_{1}^{A} A_{t-1}+\lambda_{2}^{A} B_{t-1}+\lambda_{3}^{A} A_{t-1} B_{t-1}, \\
\phi^{B} & =\lambda_{0}^{B}+\lambda_{1}^{B} A_{t-1}+\lambda_{2}^{B} B_{t-1}+\lambda_{3}^{B} A_{t-1} B_{t-1} .
\end{aligned}
$$

The corresponding multinomial logit specification is

$$
\begin{aligned}
& \log \left(\frac{P_{01}}{P_{00}}\right)=\delta_{20}+\delta_{21} A_{t-1}+\delta_{22} B_{t-1}+\delta_{23} A_{t-1} B_{t-1}, \\
& \log \left(\frac{P_{10}}{P_{00}}\right)=\delta_{30}+\delta_{31} A_{t-1}+\delta_{32} B_{t-1}+\delta_{33} A_{t-1} B_{t-1}, \\
& \log \left(\frac{P_{11}}{P_{00}}\right)=\delta_{40}+\delta_{41} A_{t-1}+\delta_{42} B_{t-1}+\delta_{43} A_{t-1} B_{t-1} .
\end{aligned}
$$


For the transition from $A_{t-1}=-1$ to $A_{t}=1$, the lagged effect of $B_{t-1}$ is $\left(\lambda_{2}^{A}-\lambda_{3}^{A}\right)$, for the transition from $A_{t-1}=1$ to $A_{t}=-1$, the lagged effect of $B_{t-1}$ is $-\left(\lambda_{2}^{A}+\lambda_{3}^{A}\right)$, and they can be expressed as linear combinations of the multinomial logit parameters. For example, $\left(\lambda_{2}^{A}-\lambda_{3}^{A}\right)$ can be expressed as

$$
\begin{aligned}
4\left(\lambda_{2}^{A}-\lambda_{3}^{A}\right) & =\left(-\delta_{22}+\delta_{32}+\delta_{42}\right)-\left(-\delta_{23}+\delta_{33}+\delta_{43}\right), \\
& =-\delta_{22}+\delta_{32}+\delta_{42}+\delta_{23}-\delta_{33}-\delta_{43},
\end{aligned}
$$

and the variance can be expressed as

$$
\begin{aligned}
\operatorname{var}\left[4\left(\lambda_{2}^{A}-\lambda_{3}^{A}\right)\right]= & \operatorname{var}\left(\delta_{22}\right)+\operatorname{var}\left(\delta_{32}\right)+\operatorname{var}\left(\delta_{42}\right)+\operatorname{var}\left(\delta_{23}\right) \\
& +\operatorname{var}\left(\delta_{33}\right)+\operatorname{var}\left(\delta_{43}\right)-2 \operatorname{cov}\left(\delta_{22}, \delta_{32}\right) \\
& -2 \operatorname{cov}\left(\delta_{22}, \delta_{42}\right)-2 \operatorname{cov}\left(\delta_{22}, \delta_{23}\right)+2 \operatorname{cov}\left(\delta_{22}, \delta_{33}\right) \\
& +2 \operatorname{cov}\left(\delta_{22}, \delta_{43}\right)+2 \operatorname{cov}\left(\delta_{32}, \delta_{42}\right)+2 \operatorname{cov}\left(\delta_{32}, \delta_{23}\right) \\
& -2 \operatorname{cov}\left(\delta_{32}, \delta_{33}\right)-2 \operatorname{cov}\left(\delta_{32}, \delta_{43}\right)+2 \operatorname{cov}\left(\delta_{42}, \delta_{23}\right) \\
& -2 \operatorname{cov}\left(\delta_{42}, \delta_{33}\right)-2 \operatorname{cov}\left(\delta_{42}, \delta_{43}\right)-2 \operatorname{cov}\left(\delta_{23}, \delta_{33}\right) \\
& -2 \operatorname{cov}\left(\delta_{23}, \delta_{43}\right)+2 \operatorname{cov}\left(\delta_{33}, \delta_{43}\right) .
\end{aligned}
$$

In the same manner, one can obtain the effect of $B_{t-1}$ on the transition from $A_{t-1}=1$ to $A_{t}=-1,-\left(\lambda_{2}^{A}+\lambda_{3}^{A}\right)$. Similarly, to obtain the differential causal effects of $A_{t-1}$ on $B_{t}$, we refer to equation (A5) with respect to $\lambda^{B}$, and solve for $\left(\lambda_{1}^{B}-\lambda_{3}^{B}\right)$ and $-\left(\lambda_{1}^{B}+\lambda_{3}^{B}\right)$.

We could also specify the differential effects of a covariate for one endogenous process by introducing the interaction between the covariate and the lagged endogenous variable. Suppose $X_{1}$ has differential effects for the endogenous process $A_{t}$. Suppressing the effect of $B_{t-1}$ and $X_{2}$, the model for $A_{t}$ and $B_{t}$ is

$$
\begin{gathered}
\phi^{A_{t}}=\lambda_{0}^{A}+\lambda_{1}^{A} A_{t-1}+\lambda_{2}^{A} X_{1}+\lambda_{3}^{A} A_{t-1} X_{1}, \\
\phi^{B}=\lambda_{0}^{B}+\lambda_{1}^{B} A_{t-1}+\lambda_{2}^{B} X_{1}+\lambda_{3}^{B} A_{t-1} X_{1} .
\end{gathered}
$$

And the corresponding multinomial logit model is

$$
\begin{aligned}
& \log \left(\frac{P_{01}}{P_{00}}\right)=\delta_{20}+\delta_{21} A_{t-1}+\delta_{22} X_{1}+\delta_{23} A_{t-1} X_{1}, \\
& \log \left(\frac{P_{10}}{P_{00}}\right)=\delta_{30}+\delta_{31} A_{t-1}+\delta_{32} X_{1}+\delta_{33} A_{t-1} X_{1}, \\
& \log \left(\frac{P_{11}}{P_{00}}\right)=\delta_{40}+\delta_{41} A_{t-1}+\delta_{42} X_{1}+\delta_{43} A_{t-1} X_{1} .
\end{aligned}
$$


For the transition from $A_{t-1}=-1$ to $A_{t}=1$, the effect of $X_{1}$ is $\left(\lambda_{2}^{A}-\right.$ $\left.\lambda_{3}^{A}\right)$, for the transition from $A_{t-1}=1$ to $A_{t}=-1$, the effect of $X_{1}$ is $-\left(\lambda_{2}^{A}+\lambda_{3}^{A}\right)$, and they can be expressed as linear combinations of the multinomial logit parameters, exactly the same as for the reciprocal causal effects of $B_{t-1}$ on $A_{t}$, as we laid out in equations (A11) and (A12).

The effects of $X_{t}$ on $B_{t}$, as expressed in the $\phi^{B}$ function, however, are NOT the differential effects for the two-way transitions of $B_{t}$ but the differential effect conditional on $A_{t-1}$, be it -1 or 1 . Conditional on $A_{t-1}=$ -1 , the effect of $X_{1}$ on $B_{t}$ is $\left(\lambda_{2}^{B}-\lambda_{3}^{B}\right)$. Conditional on $A_{t-1}=1$, the effect of $X_{1}$ on $B_{t}$ is $\left(\lambda_{2}^{B}+\lambda_{3}^{B}\right)$. Note that these conditional effects are identical in magnitude (but opposite in sign) for the two ways of transitions of $B_{t}$. Referring to equations (A11) and (A12), readers can easily write out these effects as linear combinations of multinomial logit parameter and the variance.

The last relaxation of the assumption is to allow differential effects of covariates for both endogenous processes. We extend equation (A13) into the following:

$$
\begin{aligned}
\phi^{A_{t}} & =\lambda_{0}^{A}+\lambda_{1}^{A} A_{t-1}+\lambda_{2}^{A} B_{t-1}+\lambda_{3}^{A} X_{1}+\lambda_{4}^{A} A_{t-1} X_{1}+\lambda_{5}^{A} B_{t-1} X_{1}, \\
\phi^{B_{t}} & =\lambda_{0}^{B}+\lambda_{1}^{B} A_{t-1}+\lambda_{2}^{B} B_{t-1}+\lambda_{3}^{B} X_{1}+\lambda_{4}^{B} A_{t-1} X_{1}+\lambda_{5}^{B} B_{t-1} X_{1},
\end{aligned}
$$

and the corresponding multinomial logit model becomes

$$
\begin{aligned}
\log \left(\frac{P_{01}}{P_{00}}\right)= & \delta_{20}+\delta_{21} A_{t-1}+\delta_{22} B_{t-1}+\delta_{23} X_{1} \\
& +\delta_{24} A_{t-1} X_{1}+\delta_{25} B_{t-1} X_{1}, \\
\log \left(\frac{P_{10}}{P_{00}}\right)= & \delta_{30}+\delta_{31} A_{t-1}+\delta_{32} B_{t-1}+\delta_{33} X_{1} \\
& +\delta_{34} A_{t-1} X_{1}+\delta_{35} B_{t-1} \mathrm{X}_{1}, \\
\log \left(\frac{P_{11}}{P_{00}}\right)= & \delta_{40}+\delta_{41} A_{t-1}+\delta_{42} B_{t-1}+\delta_{43} X_{1} \\
& +\delta_{44} A_{t-1} X_{1}+\delta_{45} B_{t-1} X_{1} .
\end{aligned}
$$

In this setup, the differential effects of a covariate for the two ways of transitions of one endogenous variable are also conditional on the lagged state of the other endogenous variable. Table A2 presents these conditional, differential effects more clearly.

We can express these conditional, differential effects of $X_{1}$ as linear combinations of the multinomial logit parameters, and their variances lin- 


\begin{tabular}{|c|c|c|}
\hline & -1 & 1 \\
\hline $\begin{array}{l}\text { Effects of } \mathrm{X}_{1, t-1} \text { on } A_{t} \text {, conditional on } B_{t-1} \text { : } \\
\quad \text { From } A_{t-1}=-1 \text { to } A_{t}=1 \\
\text { From } A_{t-1}=1 \text { to } A_{t}=-1\end{array}$ & $\begin{array}{l}\lambda_{3}^{A}-\lambda_{4}^{A}-\lambda_{5}^{A} \\
-\left(\lambda_{3}^{A}+\lambda_{4}^{A}-\lambda_{5}^{A}\right)\end{array}$ & $\begin{array}{l}\lambda_{3}^{A}-\lambda_{4}^{A}+\lambda_{5}^{A} \\
-\left(\lambda_{3}^{A}+\lambda_{4}^{A}+\lambda_{5}^{A}\right)\end{array}$ \\
\hline $\begin{array}{l}\text { Effects of } \mathrm{X}_{1, t-1} \text { on } B_{t} \text {, conditional on } A_{t-1} \text { : } \\
\quad \text { From } B_{t-1}=-1 \text { to } B_{t}=1 \\
\text { From } B_{t-1}=1 \text { to } B_{t}=-1\end{array}$ & $\begin{array}{l}\lambda_{3}^{B}-\lambda_{4}^{B}-\lambda_{5}^{B} \\
-\left(\lambda_{3}^{B}-\lambda_{4}^{B}+\lambda_{5}^{B}\right)\end{array}$ & $\begin{array}{l}\lambda_{3}^{B}+\lambda_{4}^{B}-\lambda_{5}^{B} \\
-\left(\lambda_{3}^{B}+\lambda_{4}^{B}+\lambda_{5}^{B}\right)\end{array}$ \\
\hline
\end{tabular}

ear combinations of the elements of the variance-covariance matrix of the multinomial logit estimation. Although the expressions are long, the logic behind them is simple and the calculations should be straightforward. Take the effect of $X_{1}$ on the transition from $A_{t-1}=-1$ to $A_{t}=1$, conditional on $B_{t-1}=-1,\left(\lambda_{3}^{A}-\lambda_{4}^{A}-\lambda_{5}^{A}\right)$, as an example:

$$
\begin{aligned}
4\left(\lambda_{3}^{A}-\lambda_{4}^{A}-\lambda_{5}^{A}\right)= & \left(-\delta_{23}+\delta_{33}+\delta_{43}\right)-\left(-\delta_{24}+\delta_{34}+\delta_{44}\right) \\
& -\left(-\delta_{25}+\delta_{35}+\delta_{45}\right), \\
= & -\delta_{23}+\delta_{33}+\delta_{43}+\delta_{24}-\delta_{34}-\delta_{44} \\
& +\delta_{25}-\delta_{35}-\delta_{45},
\end{aligned}
$$

and the variance is

$$
\begin{aligned}
& \operatorname{var}\left[4\left(\lambda_{3}^{A}-\lambda_{4}^{A}-\lambda_{5}^{A}\right)\right]=\operatorname{var}\left(\delta_{23}\right)+\operatorname{var}\left(\delta_{33}\right)+\operatorname{var}\left(\delta_{43}\right)+\operatorname{var}\left(\delta_{24}\right)+\operatorname{var}\left(\delta_{34}\right) \\
& +\operatorname{var}\left(\boldsymbol{\delta}_{44}\right)+\operatorname{var}\left(\boldsymbol{\delta}_{25}\right)+\operatorname{var}\left(\boldsymbol{\delta}_{35}\right)+\operatorname{var}\left(\boldsymbol{\delta}_{45}\right)-2 \operatorname{cov}\left(\boldsymbol{\delta}_{23}, \boldsymbol{\delta}_{33}\right) \\
& -2 \operatorname{cov}\left(\boldsymbol{\delta}_{23}, \boldsymbol{\delta}_{43}\right)-2 \operatorname{cov}\left(\boldsymbol{\delta}_{23}, \boldsymbol{\delta}_{24}\right)+2 \operatorname{cov}\left(\boldsymbol{\delta}_{23}, \boldsymbol{\delta}_{34}\right)+2 \operatorname{cov}\left(\boldsymbol{\delta}_{23}, \boldsymbol{\delta}_{44}\right) \\
& -2 \operatorname{cov}\left(\boldsymbol{\delta}_{23}, \boldsymbol{\delta}_{25}\right)+2 \operatorname{cov}\left(\boldsymbol{\delta}_{23}, \boldsymbol{\delta}_{35}\right)+2 \operatorname{cov}\left(\boldsymbol{\delta}_{23}, \boldsymbol{\delta}_{45}\right)+2 \operatorname{cov}\left(\boldsymbol{\delta}_{33}, \boldsymbol{\delta}_{43}\right) \\
& +2 \operatorname{cov}\left(\delta_{33}, \delta_{24}\right)-2 \operatorname{cov}\left(\delta_{33}, \delta_{34}\right)-2 \operatorname{cov}\left(\delta_{33}, \delta_{44}\right)+2 \operatorname{cov}\left(\delta_{33}, \delta_{25}\right) \\
& -2 \operatorname{cov}\left(\delta_{33}, \delta_{35}\right)-2 \operatorname{cov}\left(\delta_{33}, \delta_{45}\right)+2 \operatorname{cov}\left(\delta_{43}, \delta_{24}\right)-2 \operatorname{cov}\left(\delta_{43}, \delta_{34}\right) \\
& -2 \operatorname{cov}\left(\boldsymbol{\delta}_{43}, \boldsymbol{\delta}_{44}\right)+2 \operatorname{cov}\left(\boldsymbol{\delta}_{43}, \boldsymbol{\delta}_{25}\right)-2 \operatorname{cov}\left(\boldsymbol{\delta}_{43}, \boldsymbol{\delta}_{35}\right)-2 \operatorname{cov}\left(\boldsymbol{\delta}_{43}, \boldsymbol{\delta}_{45}\right) \\
& -2 \operatorname{cov}\left(\boldsymbol{\delta}_{24}, \boldsymbol{\delta}_{34}\right)-2 \operatorname{cov}\left(\boldsymbol{\delta}_{24}, \boldsymbol{\delta}_{44}\right)+2 \operatorname{cov}\left(\boldsymbol{\delta}_{24}, \boldsymbol{\delta}_{25}\right)-2 \operatorname{cov}\left(\boldsymbol{\delta}_{24}, \boldsymbol{\delta}_{35}\right) \\
& -2 \operatorname{cov}\left(\boldsymbol{\delta}_{24}, \boldsymbol{\delta}_{45}\right)+2 \operatorname{cov}\left(\boldsymbol{\delta}_{34}, \boldsymbol{\delta}_{44}\right)-2 \operatorname{cov}\left(\boldsymbol{\delta}_{34}, \boldsymbol{\delta}_{25}\right)+2 \operatorname{cov}\left(\boldsymbol{\delta}_{34}, \boldsymbol{\delta}_{35}\right) \\
& +2 \operatorname{cov}\left(\boldsymbol{\delta}_{34}, \boldsymbol{\delta}_{45}\right)-2 \operatorname{cov}\left(\boldsymbol{\delta}_{44}, \boldsymbol{\delta}_{25}\right)+2 \operatorname{cov}\left(\boldsymbol{\delta}_{44}, \boldsymbol{\delta}_{35}\right)+2 \operatorname{cov}\left(\boldsymbol{\delta}_{44}, \boldsymbol{\delta}_{45}\right) \\
& -2 \operatorname{cov}\left(\delta_{25}, \delta_{35}\right)-2 \operatorname{cov}\left(\delta_{25}, \delta_{45}\right)+2 \operatorname{cov}\left(\delta_{35}, \delta_{45}\right) \text {. }
\end{aligned}
$$


Computation of these converted parameters and their variances involves only linear operations and thus can be easily obtained using a spreadsheet such as EXCEL or by a simple program in FORTRAN, C, or other languages.

\section{REFERENCES}

Bartholomew, D. J. 1982. Stochastic Models for Social Processes, 3d ed. New York: Wiley.

Becker, Gary S. 1975. Human Capital: A Theoretical and Empirical Analysis, with Special Reference to Education. Chicago: University of Chicago Press.

Blau, David M., and Philip K. Robins. 1989. "Fertility, Employment, and Child Care Costs." Demography 26:287-99.

Bronars, S., and J. Grogger. 1994. "The Economic Consequences of Unwed Motherhood: Using Twin Births as a Natural Experiment." American Economic Review 85 (4): 1141-54.

Bumpass, Larry, and Sara McLanahan. 1989. "Unmarried Motherhood: Recent Trends, Composition, and Black-White Differences.” Demography 26:279-86.

Center for Human Resource Research. 1987a. "NLS Handbook 1987: The National Longitudinal Surveys of Labor Market Experience." Ohio State University.

— 1987b. "National Longitudinal Survey of Labor Force Behavior, Youth Survey, 1979-86." Ohio State University.

Chamberlain, Gary. 1978. "On the Use of Panel Data." Paper presented at the Social Science Research Council conference on life-cycle aspects of employment and the labor market, Mt. Kisco, N.Y.

. 1985. "Heterogeneity, Omitted Variable Bias, and Duration Dependence." Pp. 3-38 in Longitudinal Analysis of Labor Market Data, edited by J. Heckman and B. Singer. Cambridge: Cambridge University Press.

Coleman, James S. 1988. "Social Capital in the Creation of Human Capital." American Journal of Sociology 94:s95-s120.

Press.

Connelly, Rachel. 1989. "The Effect of Child Care Costs on Married Women's Labor Force Participation." Paper presented at Population Association of America conference, Baltimore.

Corcoran, Mary, and Martha S. Hill. 1985. "Reoccurrence of Unemployment among Adult Men." Journal of Human Resources 20 (2): 165-83.

Duncan, Otis D., David L. Featherman, and Beverly Duncan. 1972. Socioeconomic Background and Achievement. New York: Seminar.

Edin, K. 1991. "Surviving the Welfare System: How AFDC Recipients Make Ends Meet in Chicago." Social Problems 38 (4): 462-74.

Ellwood, David T. 1988. Poor Support: Poverty in the American Family. New York: Basic.

Finkel, Steven. 1995. Causal Analysis with Panel Data. Thousand Oaks, Calif.: Sage.

Furstenberg, F. F., J. Brooks-Gunn, and S. P. Morgan. 1987. Adolescent Mothers in Later Life. New York: Cambridge University Press.

Geronimus, A. T., and S. Korenman. 1992. "The Socioeconomic Consequences of Teen Childbearing Reconsidered." Quarterly Journal of Economics 107 (4): 11871214.

Goode, William J. 1961. "Illegitimacy, Anomie, and Cultural Penetration." American Sociological Review 16:910-25. 
Hamerle, Alfred. 1991. "On the Treatment of Interrupted Spells and Initial Conditions in Event History Analysis." Sociological Methods and Research 19 (3): 388414.

Hao, Lingxin. 1994. Kin Support, Welfare, and Out-of-Wedlock Mothers. New York: Garland.

- 1995. "How Does a Single Mother Choose Kin and Welfare Support?" Social Science Research 24:1-27.

- 1996. "Family Structure, Private Transfers, and the Economic Well-Being of Children." Social Forces 75 (1): 269-92.

Hao, Lingxin, Jacob Klerman, and Arleen Leibowitz. 1995. "Welfare and Work among Mothers of Preschoolers." Paper presented at the Population Association of America conference, San Francisco.

Hao, Lingxin, and Arleen Leibowitz. 1994. "The Role of Child Care in Employment and School Enrollment of Unmarried Mothers." Paper presented at the Population Association of America conference, Miami Beach.

Harris, Kathleen M. 1993. "Work and Welfare among Single Mothers in Poverty." American Journal of Sociology 99 (2): 317-52.

Heckman, James J. 1981. "Statistical Models for Discrete Panel Data." Pp. 114-78 in Structural Analysis of Discrete Data with Econometric Applications, edited by C. F. Manski and D. McFadden. Cambridge, Mass.: MIT Press.

Heckman, James J., and Burton Singer. 1986. "Econometric Analysis of Longitudinal Data." Pp. 1689-1763 in Handbook of Econometrics, edited by Z. Griliches and M. D. Intriligator. Amsterdam: North-Holland.

Hill, M. S., S. Augustyniak, and M. Ponza. 1987. "Effect of Parental Divorce on Children's Attainment: An Empirical Comparison of Five Hypotheses." Research report. University of Michigan, Institute for Survey Research.

Hogan, Dennis P., Lingxin Hao, and W. L. Parish. 1990. "Race, Kin Support and Mother-Headed Families." Social Forces 68 (3): 797-812.

Hsiao, Cheng. 1986. Analysis of Panel Data. Cambridge: Cambridge University Press.

Jencks, Christopher. 1992. Rethinking Social Policy. Cambridge, Mass.: Harvard University Press.

Klerman, Jacob A., and Arleen Leibowitz. 1990. "Child Care and Women's Return to Work after Childbirth." American Economic Review 80 (2): 284-88.

Kohn, Melvin L. 1969. Class and Conformity: A Study in Values. Homewood, Ill.: Dorsey Press.

Krein, S. F., and A. H. Beller. 1986. "Family Structure and Educational Attainment of Children: Differences by Duration, Age and Gender." Paper presented at the Population Association of America convention, San Francisco.

Lundberg, S., and R. D. Plotnick. 1995. "Adolescent Premarital Childbearing: Do Economic Incentives Matter?” Journal of Labor Economics 13 (2): 177-200.

Lundgren-Gaveras, Lena. 1991. "Informal Network Support, Public Welfare Support, and the Labor Force Activity of Urban Low-Income Single Mothers." Working paper. University of Chicago, Center for the Study of Urban Inequality.

Maddala, G. S. 1987. "Limited Dependent Variable Models Using Panel Data." Journal of Human Resources 22 (3): 305-38.

Marsden, Peter V., and Karen E. Campbell. 1990. "Recruitment and Selection Processes: The Organizational Side of Job Searches." Pp. 59-79 in Social Mobility and Social Structure, edited by Ronald L. Breiger. New York: Cambridge University Press.

Mason, Karen O., and Karen Kohlthau. 1989. "Determinants of Child Care Ideals among Mothers of Preschool-Aged Children." Journal of Marriage and the Family 51:593-603.

McLanahan, Sara S. 1985. "Family Structure and the Reproduction of Poverty." American Journal of Sociology 90 (4): 873-901. 
Moffitt, R. 1992. "Incentive Effects of the U.S. Welfare System: A Review." Journal of Economic Literature 30:1-61.

Montgomery, James D. 1992. "Job Search and Network Composition: Implications of the Strength-of-Weak-Ties Hypothesis." American Sociological Review 57:58696.

—. 1994. "Weak Ties, Employment, and Inequality: An Equilibrium Analysis." American Journal of Sociology 99:1212-36.

Morgan, J. N. 1982. "The Redistribution of Income by Families and Institutions and Emergency Help Patterns." Pp. 1-59 in Five Thousand American Families, vol. 10, edited by M. S. Hill et al. Ann Arbor, Mich.: Institute for Social Research.

Mueller, Charles W., and Hallowell Pope. 1977. "Marital Instability: A Study of Its Transmission between Generations." Journal of Marriage and the Family 38:8393.

Mutran, Elizabeth, and Donald C. Reitzes. 1984. "Intergenerational Support Activities and Well-Being among the Elderly: A Convergence of Exchange and Symbolic Interaction Perspectives." American Sociological Review 48:117-130.

Parish, William L., Lingxin Hao, and Dennis P. Hogan. 1991. "Family Support Networks and the Welfare and Work Experiences of Young American Mothers." Journal of Marriage and the Family 53:203-15.

Schoeni, R. F. 1994. "Does Aid to Families with Dependent Children Displace Family Assistance?" Manuscript. Rand Corporation.

Shogren, Elizabeth. 1994. "Welfare-Job Study Indicates Tough Task for Reform Plan." Los Angeles Times, April 26.

Stack, Carol. 1974. All Our Kin: Strategies for Survival in a Black Community. New York: Harper \& Row.

Stockard, Jean, and Miriam M. Johnson. 1980. Sex Roles: Sex Inequality and Sex Role Development. Englewood Cliffs, N. J.: Prentice-Hall.

Tienda, Marta, and Ronald Angel. 1982. "Headship and Household Composition among Blacks, Hispanics, and Other Whites." Social Forces 61:508-31.

Tuma, N. B., and M. T. Hannan. 1984. Social Dynamics: Models and Methods. Orlando, Fla.: Academic Press.

Uehara, E. 1990. "Dual Exchange Theory, Social Networks, and Informal Social Support." American Journal of Sociology 96:521-57.

U.S. Bureau of the Census. 1991. Statistical Abstract of the United States. Washington, D.C.: Government Printing Office.

. 1995. Statistical Abstract of the United States. Washington, D.C.: Government Printing Office.

U.S. General Accounting Office. 1994. Families on Welfare. GAO/HEHS 94-92, 94112, 94-115. Washington, D.C.: General Accounting Office.

U.S. House of Representatives. 1993. Overview of Entitlement Program, 1993 Green Book. Committee of Ways and Means. Washington, D.C.: Government Printing Office.

Wegener, Bernd. 1991. "Job Mobility and Social Ties: Social Resources, Prior Job, and Status Attainment." American Sociological Review 56:60-71.

Wilson, William Julius. 1987. The Truly Disadvantaged: The Inner City, the Underclass, and Public Policy. Chicago: University of Chicago Press.

Yamaguchi, Kazuo. 1990. "Logit and Multinomial Logit Models for Discrete-Time Event-History Analysis: A Causal Analysis of Interdependent Discrete-State Processes." Quality and Quantity 24:323-41. 